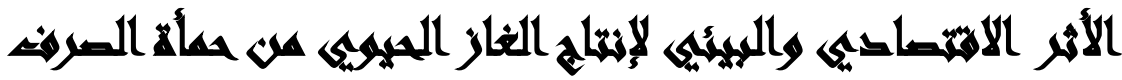

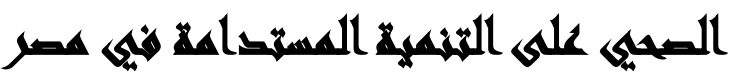

[17]

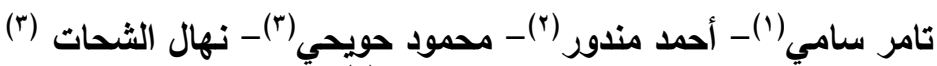

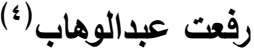

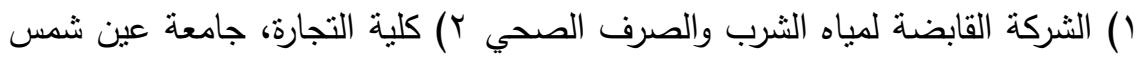

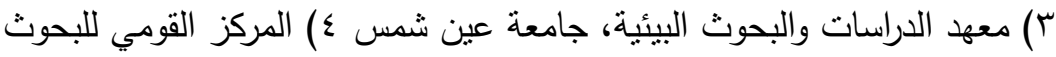

\section{المستخليك}

يستهدف هذا البحث دراسة الأثر الاقتصادي والبيئي لإنتاج الغاز الحيوي من حمأة

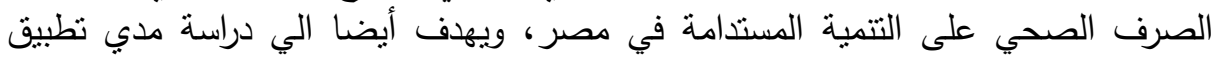

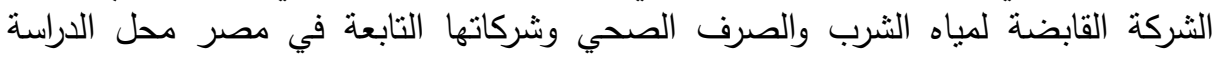

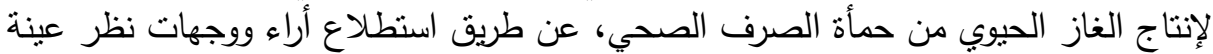

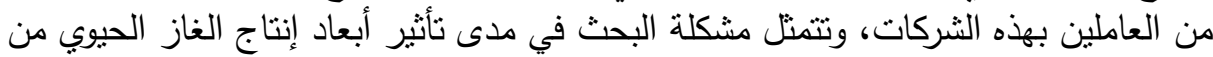

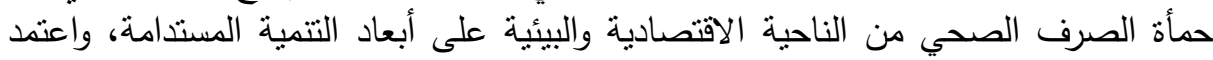

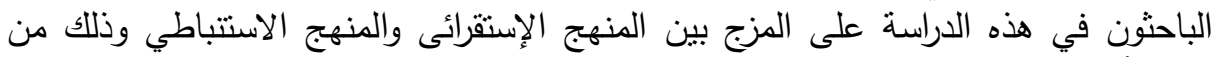

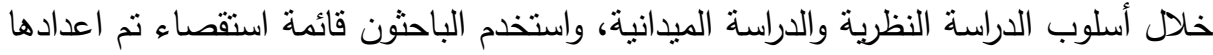

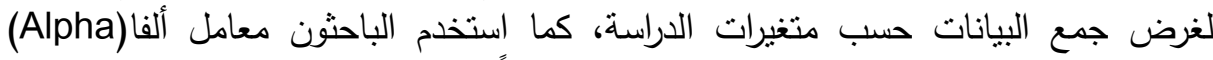

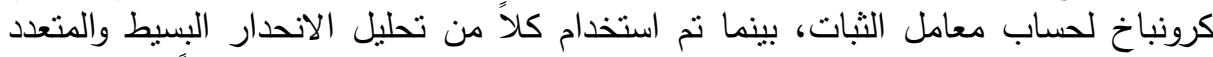

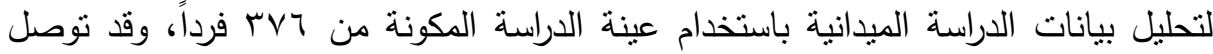

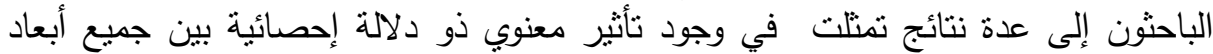

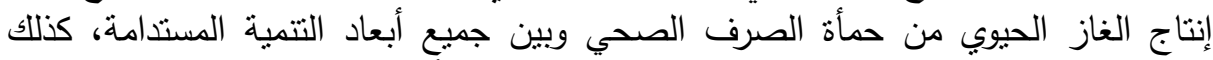

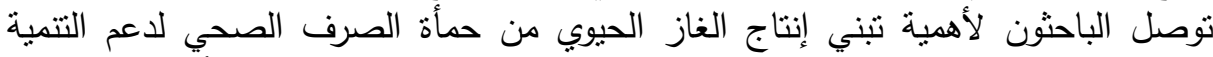

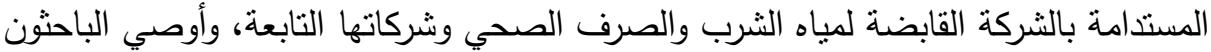

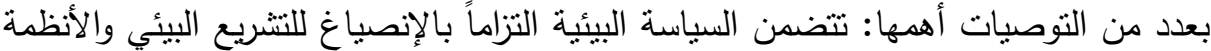

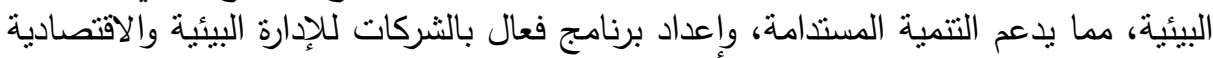
لإنتاج الغاز الحيوي من حمأة الصرف الصحي لـاعي لدعم التتمية المستدامة. 


\section{هוג}

شهدت السنوات الأخيره اهتماماً ملحوظاً بالقضايا البيئية بصفة عامة، حيث تعتبر قضية

الحفاظ على البيئة من الآثار السلبية الناتجة عن التقام التكنولوجي وتدخل الإنسان، ومن أهم الهم

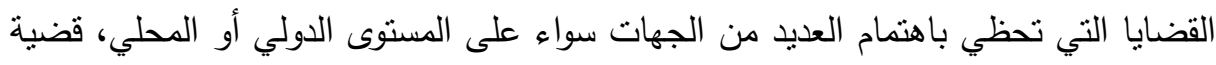

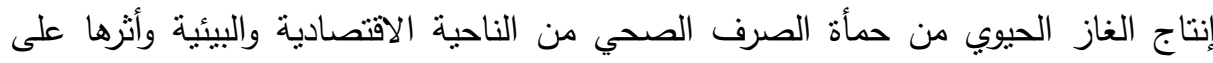
التتمية المستدامة.

وبالنظر إلي خدمات البنية الأساسية في مصر والتي تعتبر من أهم الثروط الضرورية

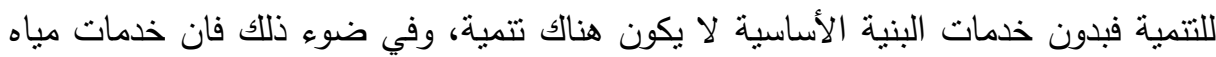

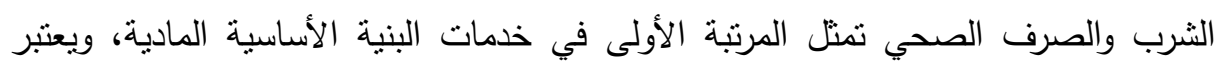
قطاع الصرف الصحي من أهم القطاعات الخدمية الحيوية التي تمس حياة الأقراد حيث برتبط ارتباطا وثثقاً بتلبية حاجات الفرد الأساسية والتي تعتبر من أساسيات الحياة، هذا بالإضافة إلى لى

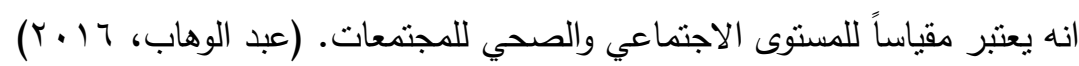

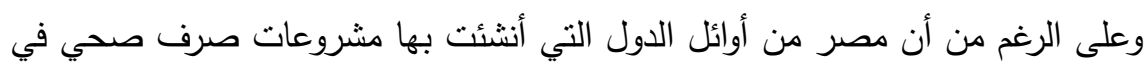

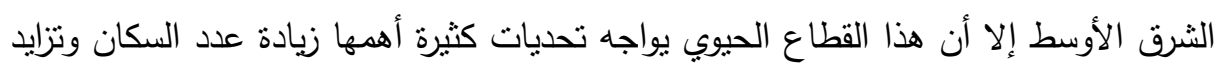
الأنشطة الصناعية والزراعية، كما أن أسعار خدماته لا تعكس التكلفة الاقتصادية للخدمة ولانا

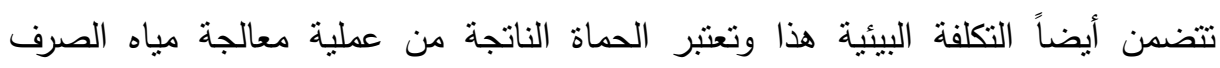

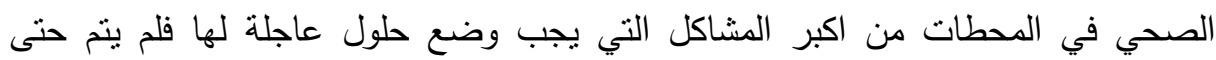

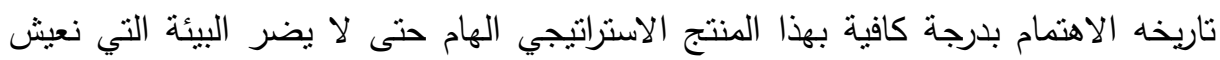

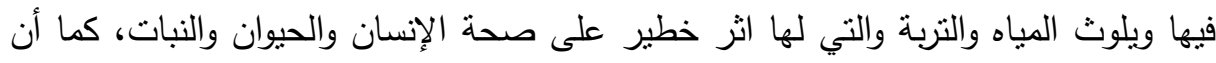

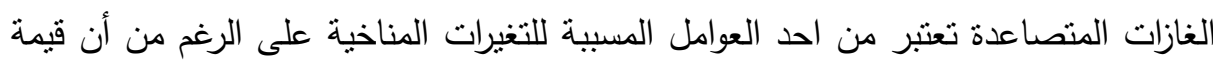

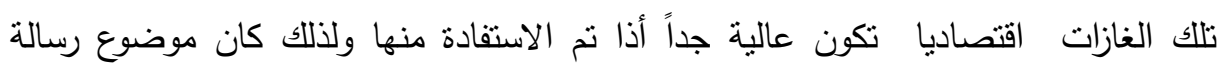

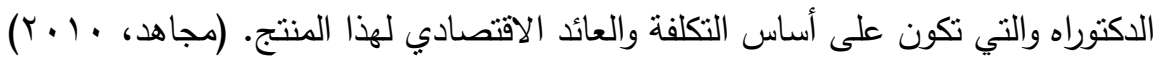
لذا يجب استخدام تقنية حيوية للاستفادة من إحدى النفايات المجتمعية الضارة التي تسبب تلوثا بيئيا يهدد صحة الإنسان في الغاز الحيوي البيوجاز الذي يتوقع حسب نتائج 
الدراسات الاقتصادية أن يعطي أكثر من نصف الطاقة وماء الري بالإضافة إلي إنتاج سماد

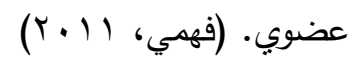

من هذا المنطلق فإن هذه الدراسة لقياس الأثر الاقتصادي والبيئي لإنتاج الغاز الحيوي

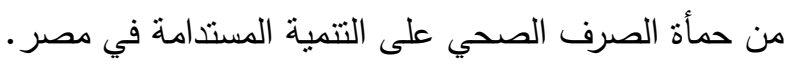

\section{2.}

قام الباحثون بدراسة استطلاعية ميدانية لتحديد مشكلة الدراسة باستخدام قائمة استقصاء

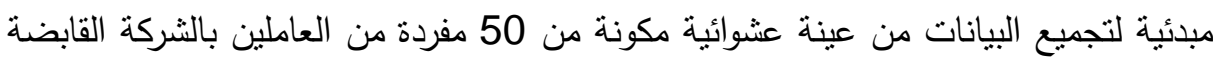
لمياه الثرب والصرف الصحي وشركاتها التابعة، بهدف تقييم درجة نوافر أبعاد التتمية

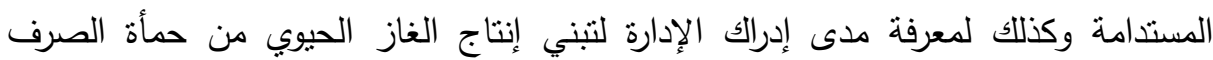
الصحي من الناحية الاقتصادية والبيئية. يمكن توضيح نتائج ما توصلت إليه الدراسة الاستطلاعية في "انخفاض مستوى إدراك

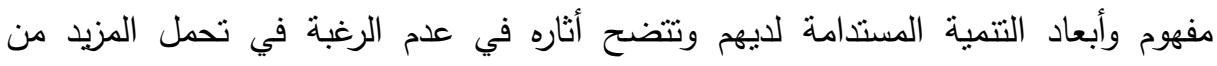
المسئوليات البيئية والاقتصادية، فضلا عن ضعف الالنزام البيئي، وزيادة معدل التلوث الناتج

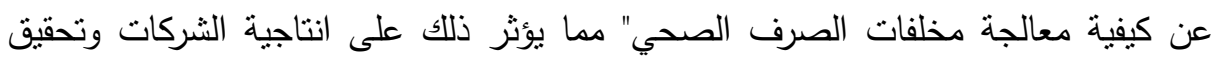
العوائد المطلوبة، والآثار البيئية والاقتصادية التتمية المستدامة.

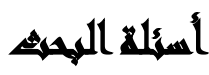

يحاول الباحثنون من خلال هذه الدراسة الإجابة على التساؤل الرئيسي التالي: ما الأثر

الاقتصادي والبيئي لإنتاج الغاز الحيوي من حمأة الصرف الصحي على هلى التتمية المسندامة؟ الصابه

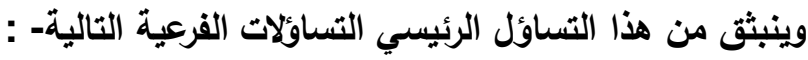

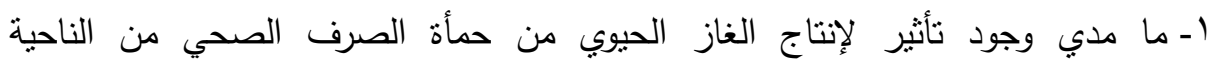

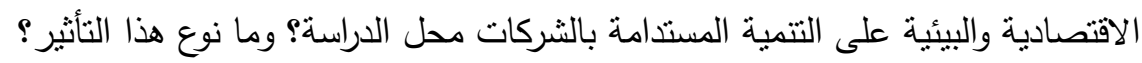
r- ما المستوى الاقتصادي والبيئي اللازم لإنتاج الغاز الحيوي من حمأة الصرف الصنيه الصحي في

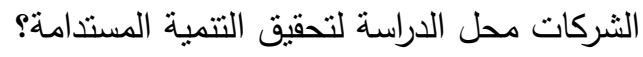

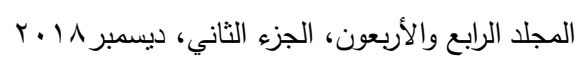




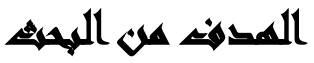

يهدف هذا البحث بشكل عام إلى دراسة واقع تبني الثركة محل الدراسة لإنتاج الغاز

الحيوي من حمأة الصرف الصحي وأثز ذلك على التتمية المستدامة، كما نذكر من أهدافه: ا - قياس تأثير أبعاد إنتاج الغاز الحيوي من حمأة الصرف الصحي على التتمية المستدامة بالثركات محل الدراسة.

r- دراسة مدي إدرالك إدارات هذه الثركات في الوفاء بمسئوليتها تجاه المجتمع والبيئة.

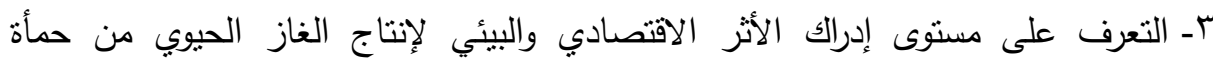
الصرف الصحي والتتمية المستدامة بالثركات محل الدراسة.

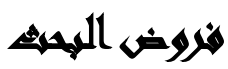

لتحقيق أهداف الاراسة والإجابة عن تساؤلاتها، فقد تم بناء الفروض التالية: الفرض الرئيسي الأول: لا يوجد تأثيراً ذات دلالة إحصائية للسياسة البيائية كأحد أبعاد إنتاج

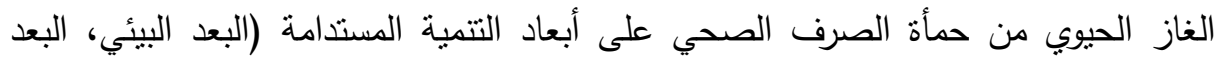
الاقتصادي والتقني، البعد الاجتماعي) في الثركات محل الدراسة. الفرض الرئيسي الثاني: لا يوجد تأثيراً ذات دلالة إحصائية للتخطبط كأحد أبعاد إنتاج الغاز الحيوي من حمأة الصرف الصحي على أبعاد التتمية المستدامة.

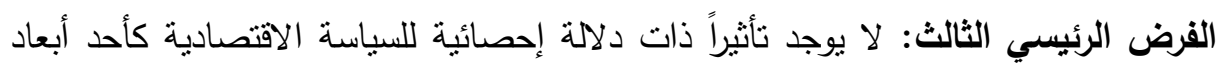

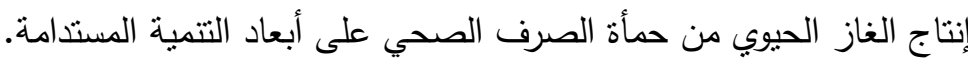

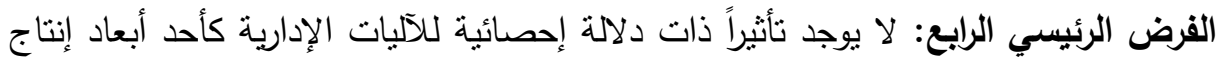
الغاز الحيوي من حمأة الصرف الصحي على أبعاد التتمية المستدامة. الفرض الرئيسي الخامس: لا يوجد ثأثيراً ذات دلالة إحصائية للمراجعة الإدارية والبيئية كأحد أبعاد إنتاج الغاز الحيوي من حمأة الصرف الصئي الصامي على أبعاد التتمية المستدامة. 


\section{أهمية المهنه}

تتبع أهمية البحث من الدور الذي تلعبه عمليات إنتاج الغاز الحيوي من حمأة الصرف الصحي في مواجهة ما يشهاه العالم في تغيرات بيئية بسبب النطور التكنولوجي في المجال

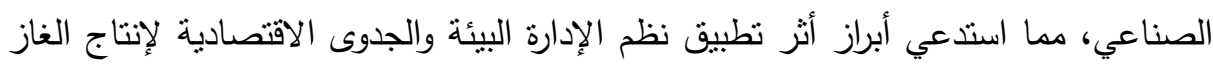

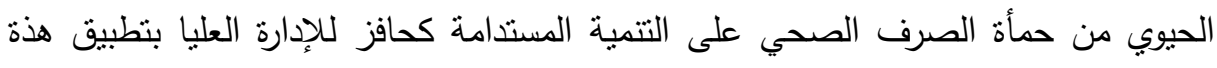
النظم، وتتقسم أهمية الدراسة إلى أهمية علمية وأهمية تطبيقية، ونتشمل ما يلي: الأهمية العلمية: تتمثل أهمية هذه الدراسة على المستوي العلمي فيما يلي:

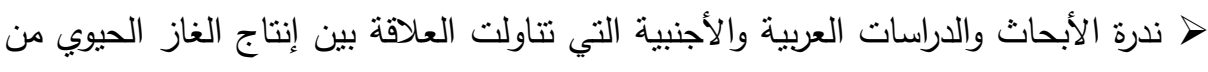

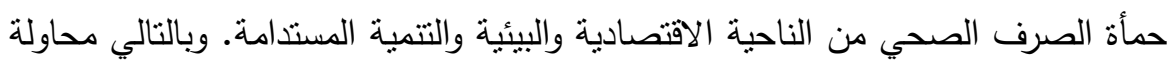
المساهمة في علاج الفجوة البحثية المتعلقة بإنتاج الغاز الحيوي من حمأة الصرف الصحية ولئي ولئي وعلاقتها بالتنمية المستدامة. > التعرف على أثر تبني إنتاج الغاز الحيوي من حمأة الصرف الصحي من الناحية الاقتصادية والبيئية على التتمية المستدامة.

الأهمية العملية: تتمنل أهية هذه الدراسة على المستوي التطبيقي فيما يلي: > إيضاح دور إنتاج الغاز الحيوي من حمأة الصرف الصحي من الناحية الاقتصادية والبيئية

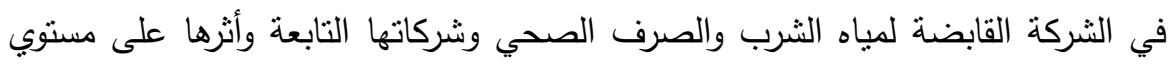
التنمية المستدامة.

> أهمية القطاع محل الدراسة فهو يعد من القطاعات الحساسة والمهمة، لما لذلك القطاع من أهمية على صعيد التتمية الاقتصادية المستدامة، وعليه فإن أهمية هذا القطاع، يدعو إلى ولى إجراء منل هذا النوع من الدراسات لضمان استمراريته وتطويره.

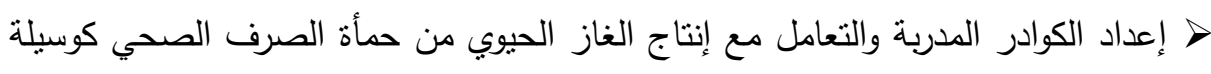
فاعلة، إضافة إلى أهمية تنبي إنتاج الغاز الحيوي من حمأة الصرف الصدي الصحي كعامل مساعد في تحقيق التتمية الاقتصادية المستدامة، مما يساعد تللك المؤسسات في تحقيق إنىاج أهدافها الاستراتيجية.

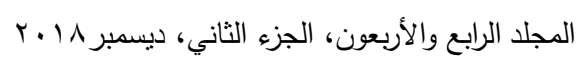




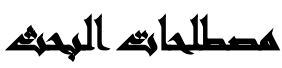

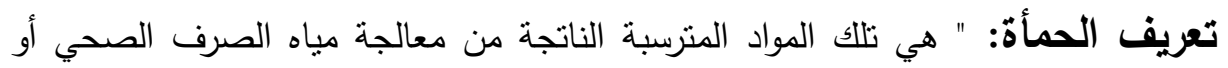

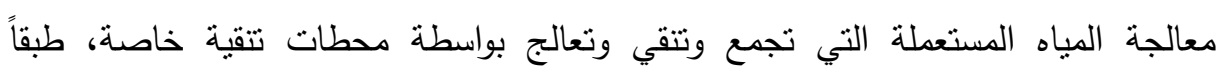

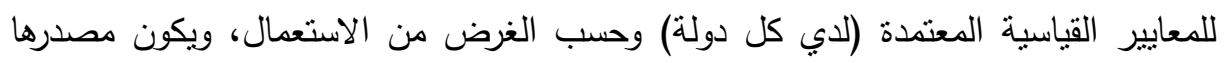

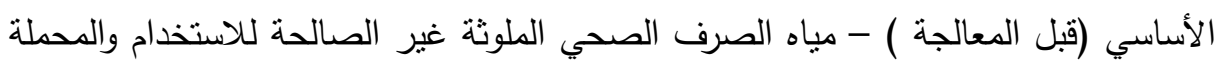

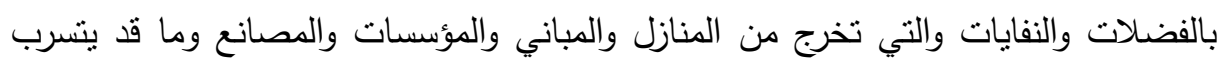

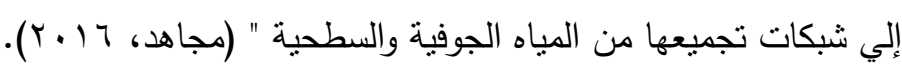

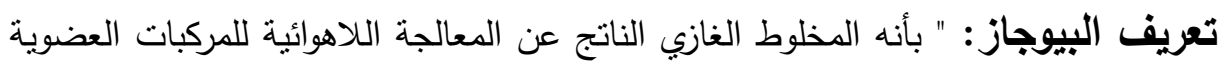

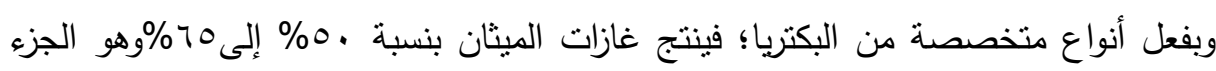

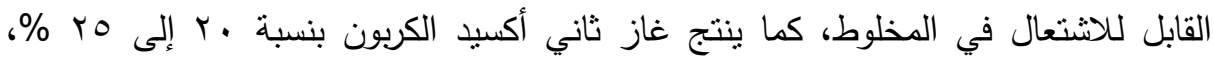

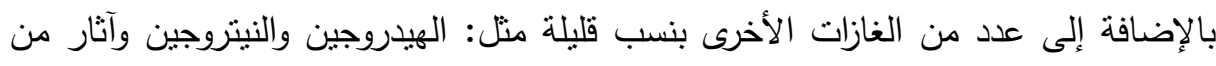

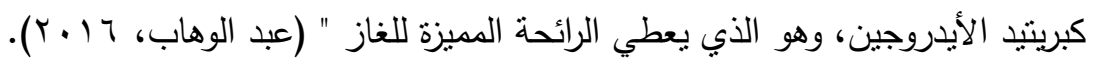

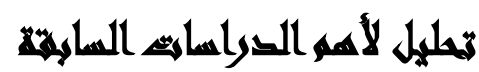

> الدراسات المتعلقة بإنتاج الغاز الحيوي من حمأة الصرف الصحي:

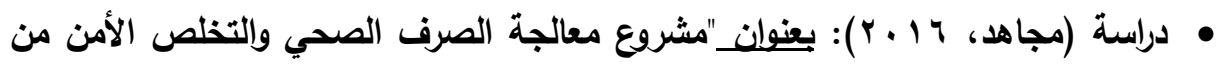

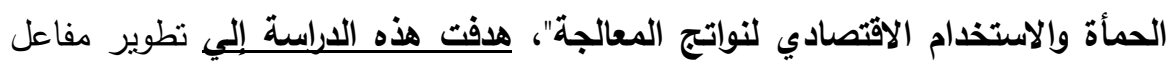

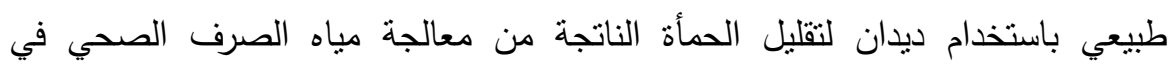
محطات الصرف الصحي للتخلص من الحمأة بطريقة طبيعية وبأقل تكلفة وذلك للاستفادة

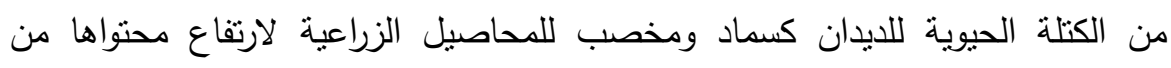
عنصري الفسفور والنيتروجين.

وكانت أهم النتائج أنه نظرا لارتفاع محتوي الديدان من البروتين والأحماض الامينية فإنها

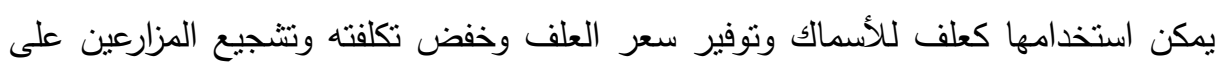


الاستزراع السمكي نظرا لارتفاع أسعار مسحوق السمك المكون الرئيسي لأعلاف الأسماك إلي .

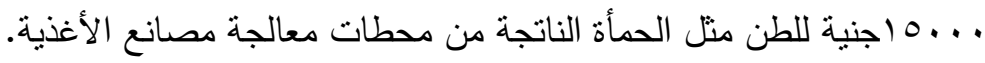
أوجه الاختلاف: تختلف الدراسة السابقة عن الدراسة الحالية في انها تتعرض للتخلص التهن الآمن من الحمأة عن طريق مفاعل طبيعي باستخدام الديدان لتمريدها لتكون غذاء للأسماك بديلا عن الأعلاف ويعتبر العائد الاقتصادي من وراء ذلك اقل بكثير من التخلص منها عن طريق بأن البيوجاز والسماد الزراعي. • دراسة (إمام، 11 (Y) ، بعنوان " نموذج مطور لوحدة بيوجاز إرشادية ذات كفاة عالية لإنتاج طاقة جديدة وسماد معالج"، هدفت الدراسة الي تحسين الوضع البيئي بالمزارع الحيوانية، كما هدفت الي إنتاج طاقة جديدة ومتجددة من مخلفات المزارع الحيوانية، وإنتاج سماد عضوي معالج يحسن من الإنتاجية الزراعية. أهم النتائج: • ت تم عمل التحاليل اللازمة الأولية للتشغيل. • تم وضع الرسومات الهنسية اللازمة لإنشاء وحدة البيوجاز المطورة. • تم شراء معدات القياس المطلوبة.

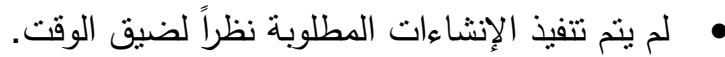

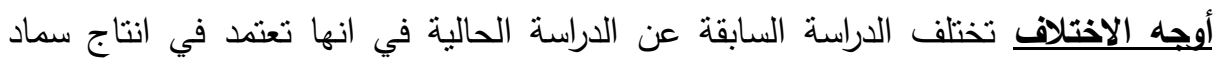
عضوي معالج يحسن من الإنتاجية الزراعية فقط وإنتاج طاقة جديدة ومتجددة من مخلفات المزارع فقط بعكس الدراسة الحالية والتي تعمل على مخلفات الصرف التراعه الصحي من محطات معالجة الصرف الصحي بمصر كما أنه اعتمد على مخلفات المزارع والتي هي اقل ضرلى ضراً

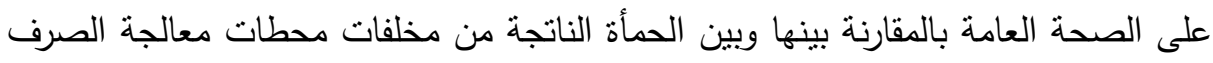

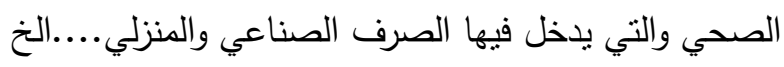

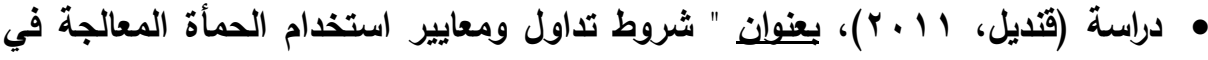
مصر"، هدفت الي دراسة شروط تداول ومعايير استخدام الحمأة المعالجة في مصر ، من حيث أنه لا يسمح بإلقاء الحمأة في المجاري المائية أو المصارف، وكذلك برائ براعى غسل

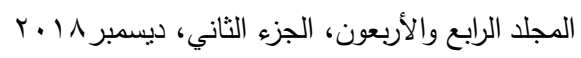


العربات المستخدمة في نقل الحمأة وصرف مياه الغسيل الى وحدات المعالجة أو الثبكة في مواقع الاستخدام أو التخزين أو الإنتاج، كما هدفت دراسة أنه يحظر استخدام الحمأة المستخرجة من الترانشات في الزراعة مباشرة ويجب عمل المعالجة اللازمة ومطابقتها للمعايير الواردة بالكود المصري رقم 1.0 لسنة هـ ـ. ب، وارتداء الملابس الواقية أثناء استخدام الحمأة مثل الأقنعة والقفازات والأحذية.

أهم النتائجج

• لا يسمح برعي المحاصيل المستخدمة كعلف للماشية إلا بعد مرور شهرين من استخدام الحمأة وأخر رية. • أثارت الدراسة إلي أن لا تستخدم الحمأة في زراعة محاصيل الخضر الورقية التي تستخدم في السلاطة مثل الخس ومحاصيل الفاكهة الملامسة للتربة مثل الفراولة أو المحاصيل الدرنية والجذرية مثل البطاطس والجزر واللفت والفول السوداني.

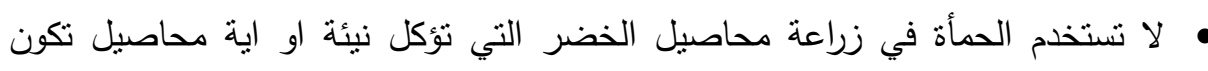

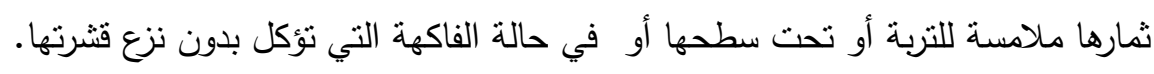
• • ل الخزن الحمأة بالقرب من المصارف وقنوات الري ومصادر المياه. أوجه الاختلاف:تختلف الدراسة السابقة عن الدراسة الحالية في أنها تعتمد على إظهار الظهار

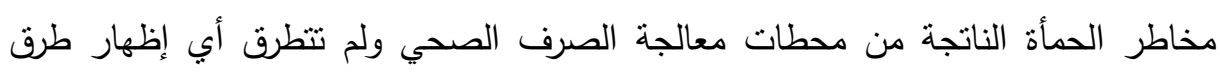

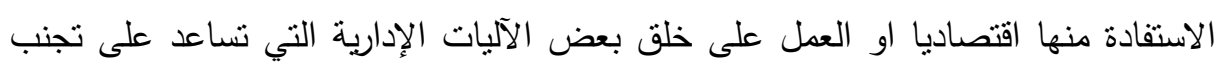
تلك المخاطر التي سبق الإثارة إليها بعالية.

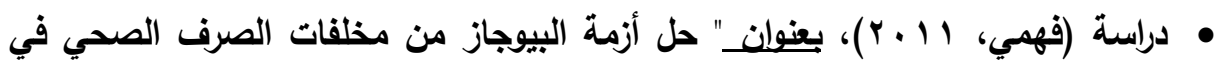

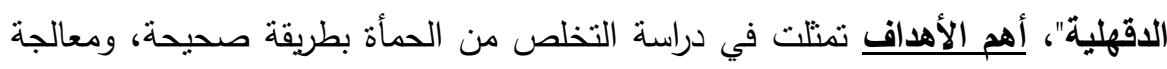

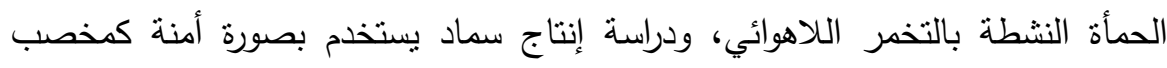

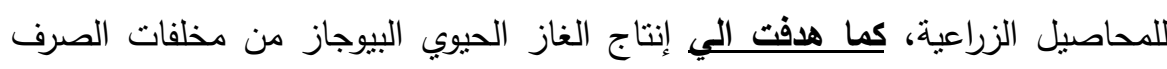

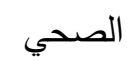

أهم النتائج: أثشارت الدراسة إلي أن متوسط الحمأة الناتجة من محطات الصرف الصحي على

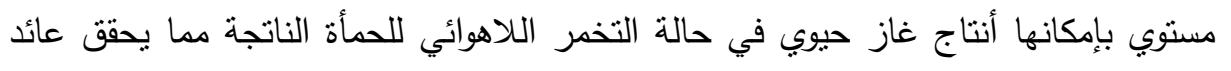
436

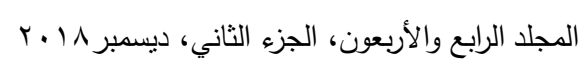


اقتصادي مأمولا سواء للطاقة المنتجة بالإضافة ألي أنتاج سماد امن يحتوي على عناصر تأمين نمو وتغذية النباتات.

أوجه الاختلاف: تختلف الدراسة السابقة عن الدراسة الحالية في أنها تعتمد بين علاقة التزايد المطرد في عدد السكان وزيادة أنتاج الحمأة من محطات الصرف الصحي بمحافظة الدقهلية مجمعة والمنصورة على وجه الخصوص أما في الدراسة الحالية في دراسة مقارنة بين محافظات مصر كلها وأثز ذللك اعلى الاقتصاد بوجه عام في مصر .

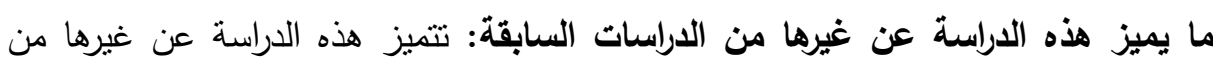

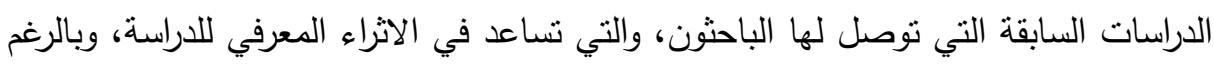

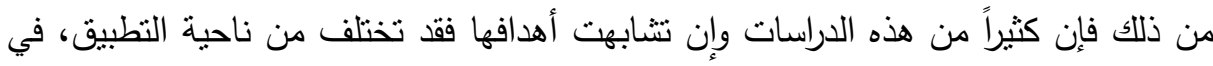
المكان والزمان، وحجم العينة، ومتغيرات أخري. لذللك يمكننا القول إن هذه الدراسة اتسمت بمجموعة من الخصائص التي جعلتها تتميز

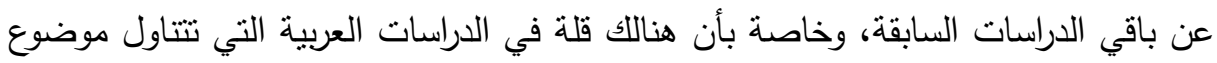
تبني إنتاج الغاز الحيوي من حمأة الصرف الصحي والتتمية المستدامة كمتغير تابع وأحياناً

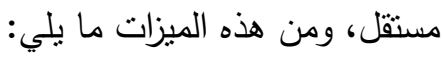
• تميزت هذه الدراسة باختبارها بالمجتمع الذي طبقت عليه، حيث تمت الدراسة على الثركة

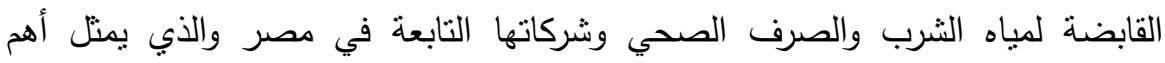
القطاعات الاقتصادية والتي لها تأثير مباشر على البيئة.

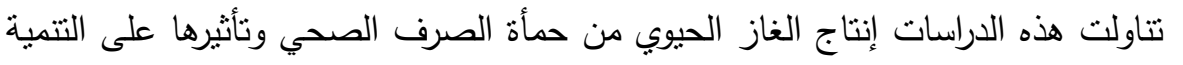
المستدامة، وعلى حسب علم الباحثين بأنه لا يوجد دراسة في الوطن العربي عامة ومصر خاصة تتاولت ذلك. تساهم هذه الدراسة في رفع المخزون المعرفي حول واقع تبني إنتاج الغاز الحيوي من حمأة الصرف الصحي، لذا يحاول الباحثون من خلال هذه الدراسة الكثف عن التهن الممارسات الخاصة بذلك المفهوم وأهم معوقاته وسبل نطبيقة في قطاع التطبيق من أجل بناء إطار 
متكامل لتطبيق هذا الفكر بناءً على أسس علمية سليمة وهو ما لم تتتاوله الدراسات السابقة من قبل على حد ما وصل اليه الباحثون من دراسات.

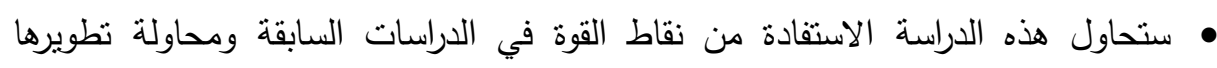

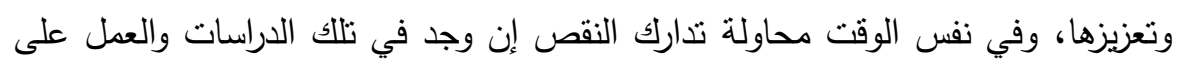

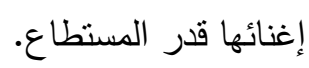

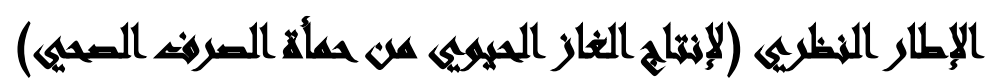

يستعرض الباحث الإطار النظري للبحث من خلال النقاط التالية: أولاً: إنتاج الغاز الحيوي: تطلق كلمة البيو غاز - الغاز الحيوي على مجموعة من من فلإل الغازات الناجمة عن تخمر وتحلل المواد العضوية بفعل بكتيريا لاهوائية بمعزل عن الهواء. يتكون الغاز الحيوي من خليط من الغازات وهي: غاز الميثان، ثاني اكسيد الكربون، الهيدروجين ، النيتروجين وكبرينيد الهيدروجين. تكون نسب هذه الغازات متفاوتة تبعا لمكونات

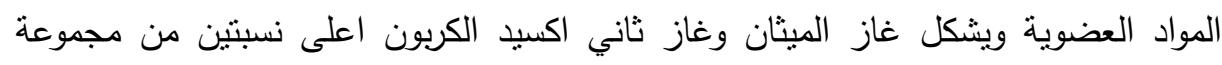

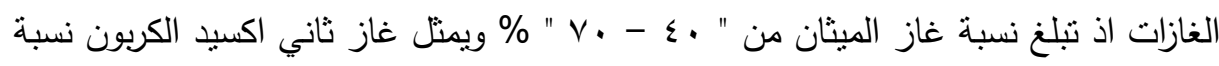

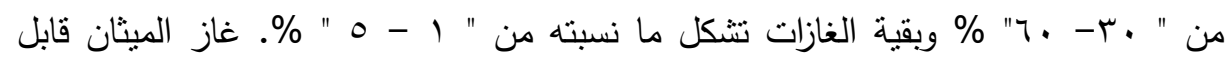

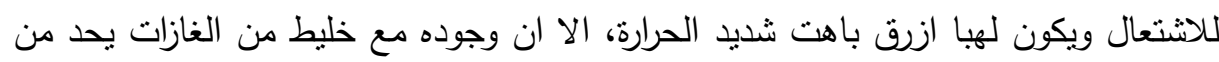

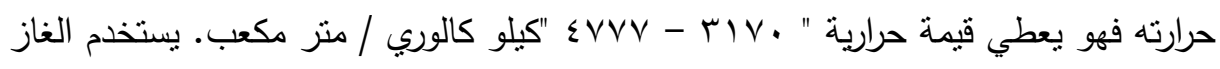
الحيوي في طهي الطعام والانارة والتدفئة وتتشغيل محركات تعمل على الاحتراق الداخلي

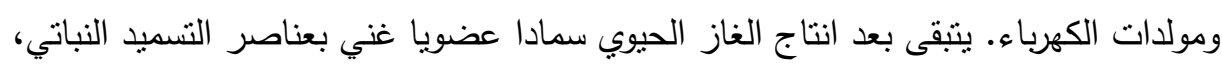

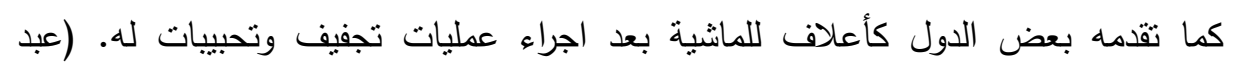

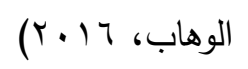

وتتتج محطات معالجة مياه الصرف الصحي بجمهورية مصر العربية كميات هائلة من الحمأة سنويا يجب الاستفادة منها اقتصاديا والتخلص منها بشكل أمن لحماية البيئة من التلوث

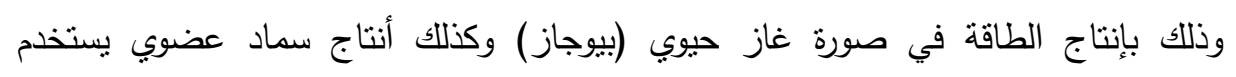


لتخصيب التربة وفي هذا الثأن سوف يتم دراسة الأثر البيئي الناتج عن ذلك من حيث الملوثات والإضرار الناتجة عن نراكم الحمأة في محطات المعالجة.

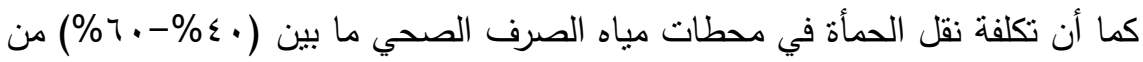
تكاليف التشغيل الكلية لذلك التخلص من الحمأة بطرق اقتصادية تقلل من التكلفة ونحافظ غلي البيئة أمرا هاما يجب مراعاته في حل المشاكل الحالية الناتجة من مياه الصرف الصحي حيث مني الصني تعتبر مخاطر ومثكلات الصرف الصحي على المستوي العالمي اكبر مصدر للنلوث من من مناه حيث الحجم مع نزايد الصرف من البلدان النامية نتيجة للنوسع العمراني السريع وتزايد السكان وانعدام القدرات والتخطيط والتمويل اللازمة لإقامة شبكة الصرف الصحي ومعامل معالجة

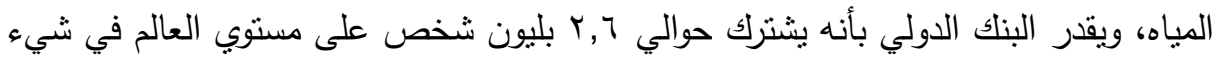

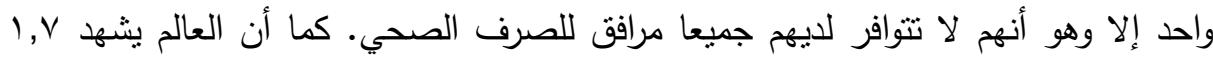

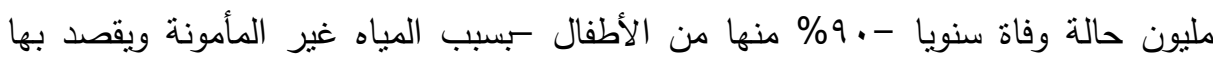

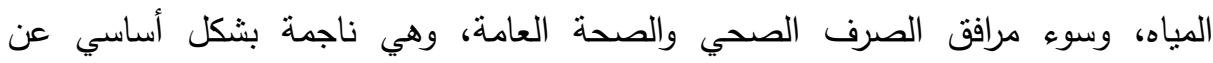
الإصابات بأمراض الإسهال المعدي. ومن شأن توفير مرافق الصرف الصحي وتهي وترسيخ ممارسات الصحة العامة الجيدة، بما يعادل مرثين ونصفاً العجز في الحصول على على العين المياه

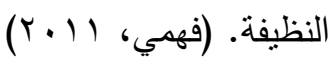
ويلزم القانون الخاص بالصرف الصحي التخلص الأمن من الحمأة الناتجة عن الصرف الصحي في مصر، وهو ما يمثل مشكلة أساسية من المشكلات التي تعيق العمل في هذا لهن القطاع الحيوي، وهناك بعض النصوص المتتاثرة هنا وهناك في عدد من القوانين والتي تخص

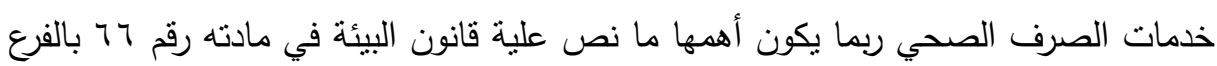
الثالث حول التلوث بمخلفات الصرف الصحي والقمامة بأنه يحظر على السفن والمنصات البحرية تصريف مباه الصرف الصحي الملوثة داخل البحر الإقليمي والمنطقة الاقتصادية الخالصة لجمهورية مصر العربية ويجب التخلص منها طبقا للمعايير والإجراءات التي تحدد اللائحة التتفيذية لهذا القانون، وقد أوضح تقرير التتمية البشرية للأمم المتحدة أن اللافت للنظر غياب السياسات الوطنية الفعالة بصورة اكبر في الصرف الصحي عنة في المياه خاصة أن

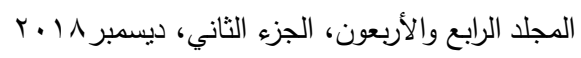


هناك علاقة قوية بين ضعف الوصول لياه الثرب وخدمة الصرف الصحي، والنواحي الصحية وبخاصة بين الأطفال دون سن الخامسة.

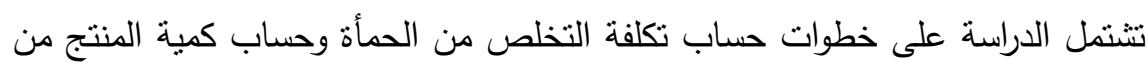

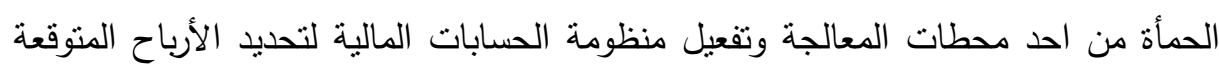
من أنتاج البيوجاز وتوفير الطاقة البديلة للكهباء وكذلك أنتاج السماد، فضلا عندة عن التحسن

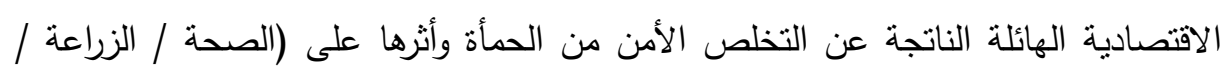

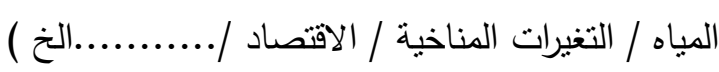
كما تعثبر الحمأة (Sludge)عبئا ثقيلا على كاهل البيئة، والتخلص منها معضلة تواجه

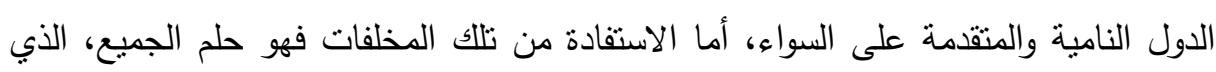

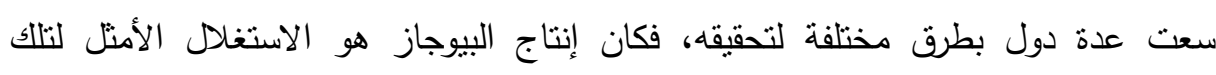

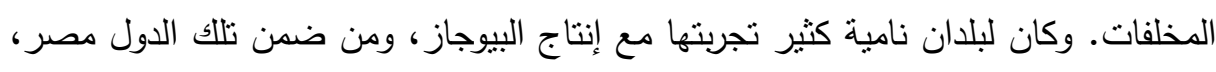

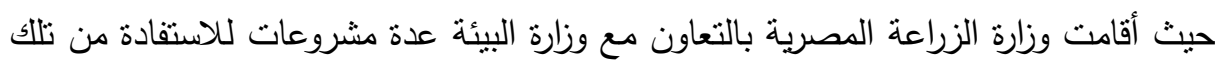

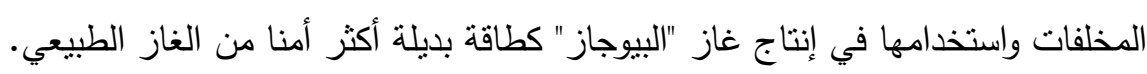

\section{إجراعاهت الفراسها}

اعتمد الباحثون في هذه الدراسة على المزج بين المنهج الإستقرائى والمنهج الاستتباطي

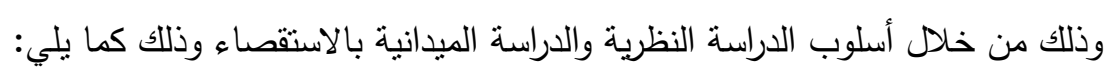
الدراسة النظرية (المنهج الوصفي): في هذا الإطار إعتمت الدراسة على المنهج

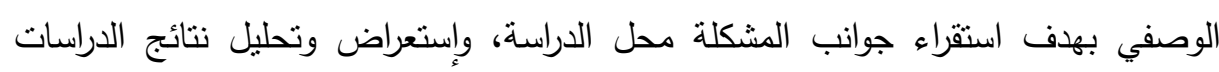

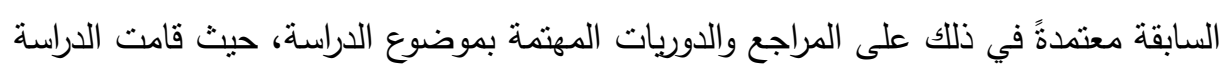
بالتعرف على الجوانب المختلفة للمشكلة موضوع الدراسة، بالإضافة إلى الدراسات التى أعدتها

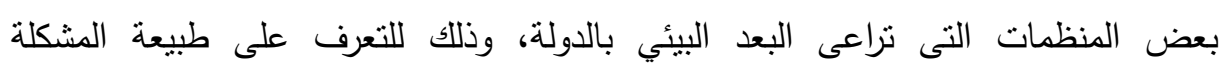
والظروف المحيطة بها والمؤثرة عليها، وقد إعتمد الباحثن على على بعض البذ المراجع العربية

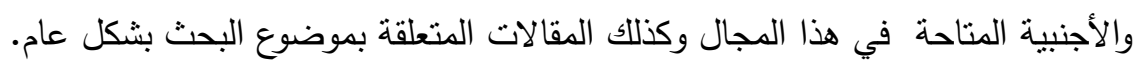


الدراسة الميدانية (المنهج التحليلي): اعتمد الباحثون في إجراء الدراسة الميدانية على قائمة الاستقصاء والتي تم توزيعها على عينة من الثركات محل الدراسة، وذلك في الفترة من

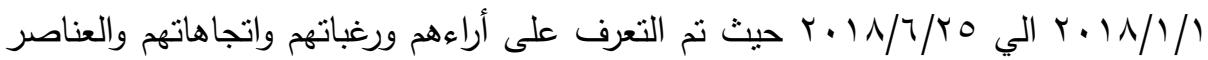
الغير مرضية التى نواجههم وانطباعاتهم واقتراحاتهم، وقد نم استخدام الأساليب الإحصائية في تحليل البيانات والمعطيات التي تم جمعها. قد توصلت الدراسة إلى وجود فجوة بحثية لم تغطيها العديد من الدراسات السابقة، ومن ثم اهتمت الدراسة بإجراء دراسة إستكثافية في المجال التطبيقي، ثم تم استعراض نتائج الدراسة الميدانية وتحليلها، ومن ثم فإن الدراسة قد تتاولت ذلك في موضوعين أساسيين هما: أسس درس الدراسة الميدانية، ونتائج الدراسة الميدانية ومناقتشها، حيث استخدم الباحثون الأسلوب الإحصائي الأنسب للتحليل، وهو معامل ألفال(Alpha) كرونباخ لحساب معامل الثبات، بينما استخدم كلاً من معامل الارتباط لبيرسون، وأسلوب تحليل الإنحدار البسيط والمتعدد لتحليل بيانات الدراسة الميدانية، ولما كانت البيانات قد جاءت منظمة في شكل جداول تكرارات من

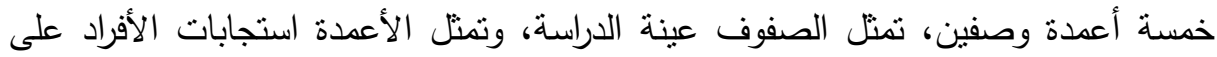
أسئلة الاستقصاء والتى تم ترنيبها تتازلياً من موافق تماماً إلى لا أوافق مطلقاً.

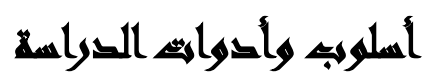

مجتمع الاراسة وإلعينة: يمكن نوضيح كلاً من مجتمع وعينة الدراسة كما يلي: • مجتمع الدراسة: يتمنل مجتمع الدراسة في العاملين بالثركة القابضة لمياه الثرب والصرف الصحي والثركات وشركاتها التابعة، وقد نم اختيار الفئات الثلاثة (مديرون-

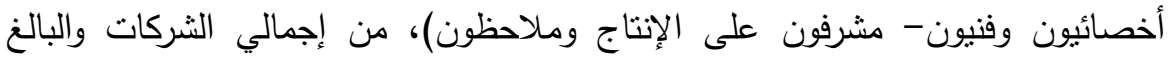
عددها 25 شركة، وإجمالي عدد الفئات الثلاثة مبر ـ. موظف وهذا الاستهداف لهذا العدد سيعطي نتائج دقيقة، وهم القادرون على فهم وإدراك متغيرات الدراسة وفيما يلي البيانات المتعلقة بهذه الثركات في الجدول رقم (1) التنالي: 
تامر سامي وآخرون

جدول رقم(1): عدد العاملين حسب الثركات التابعة بمجتمع الدراسة

\begin{tabular}{|c|c|c|c|}
\hline النسبة المئوية & عدد العاملين & الشــــــــة & s \\
\hline$\% 10.36$ & $\overline{6304}$ & القاهرة & \\
\hline$\% 7.56$ & 4600 & الإسكندرية & \\
\hline$\% 2.81$ & 1712 & دمياط & \\
\hline$\% 5.98$ & 3638 & الاقهلية & \\
\hline$\% 5.73$ & 3484 & النشرقية & \\
\hline$\% 4.21$ & 2561 & القليوبية & \\
\hline$\% 2.92$ & 1779 & كفر الشيخ & \\
\hline$\% 5.39$ & 3280 & الغربية & \\
\hline$\% 5.68$ & 3456 & المنوفية & \\
\hline$\% 5.30$ & 3226 & البحيرة & \\
\hline$\% 3.25$ & 1979 & محافظات القناة & \\
\hline$\% 3.85$ & 2342 & الجيزة & \\
\hline$\% 3.52$ & $\frac{2141}{2141}$ & بني سويف & \\
\hline$\% 2.70$ & 1644 & بكي الفيوم & \\
\hline$\% 3.91$ & 2378 & المنيا & \\
\hline$\% 3.97$ & 2414 & أسيوط والوادي الجديد & \\
\hline$\% 5.37$ & 3266 & سوهاج & \\
\hline$\% 3.68$ & 2237 & قتنا & \\
\hline$\% 5.02$ & 3053 & اسوان & \\
\hline$\% 2.15$ & 1305 & الاقصر & \\
\hline$\% 1.78$ & 1080 & البحر الاحمر & \\
\hline$\% 2.26$ & 1373 & مطروح & \\
\hline$\% 2.61$ & 1586 & سيناء & \\
\hline$\% 100$ & 60838 & الاجمالح & \\
\hline
\end{tabular}

المصدر: من إعداد الباحثين من واقع بيانات إدارة الموارد البشرية بالثركة القابضة

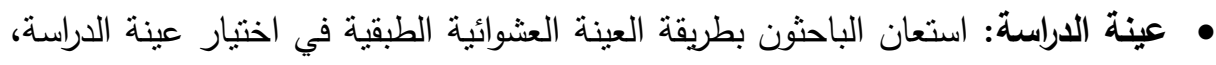
وقد استخدم الباحثون طريقة النسب والتتاسب، وتم اختيار عينة من مجتمع الدراسة باستخدام معادلة روبيرت ماسون، وذللك بمعلومية حجم المجتمع الذى يبلغ مبه ـ ـ مفردة، وعند مستوى نقة 95\% وحدود خطأ 土 5\%، وبعد ادخال البيانات للبرنامج نم حساب حجم العينة وبلغ 382 مفردة نقريباً، وكانت عدد الاستمارات الصحيحة التى تم استردادها هي 309 استمارة، وقد أجري التحليل الإحصائي على الاستمارات التي أمكن للباحثين

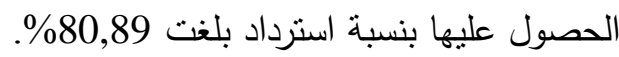


• قياس متغيرات الدراسة: في ضوء الدراسات السابقة التي اطلع عليها الباحثّن، فقد اعتمد

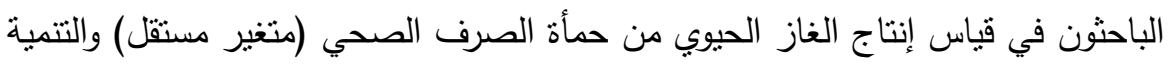
المستدامة (متغير تابع) على الأبعاد التالية:

• المتغير المستقل: (إنتاج الفاز الحيوي من حمأة الصرف الصحي): تمنتله الأبعاد الخمسة التالية: (السياسة البيئية - التخطبط -السياسة الاقتصادية -الآليات الإدارية -المراجعة الإدارية والبيئية). • المتغير التابع: (التنمية المستدامة): من خلال الأبعاد الثلاثة التالية: (البعد البيئي -البعد

$$
\text { الاقتصادي والثقني -البعد الاجتماعي). }
$$

أداة تجمبع بيانات الدراسة المبدانبة: قام الباحثون بتصميم قائمة استقصاء لتجميع البيانات من مفردات البحث، حيث مر إعدادها وتصميمها بالخطوات التالية: الخطوة الأولحي: إعداد قائمة الاستقصاء في صونتها الأولية: إعتمد الباحثون نصميم قائمة

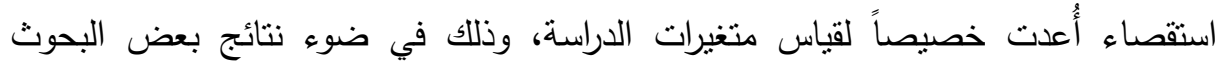
والدراسات والكتابات العلمية السابقة، وكذلك في ضوء ما كثفت عنه نتائج الدراسة الاستطلاعية. قد تم صياغة عبارات الاستقصاء بأسلوب خبرى وبألفاظ سهلة وبسيطة حتى تتفق مع المستوى الثقافي لبعض العاملين موضع البحث، هذا وقد بلغ عدد هذه العبارات 9 ؛ عبارة.

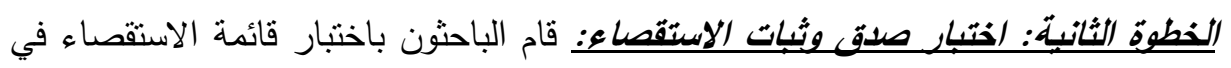
صورتها المبدئية من خلال التعرف على صدقها وثناتها وذللك على النحو التالى:

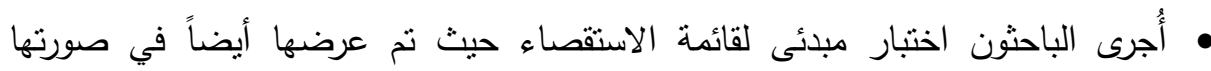
الأولية على هب من العاملين بالثركة محل الدراسة، وذلك للتأكد من بساطة الصبائية الصياغة ووضوح اللغة، وللتأكد أيضاً من صلاحية الاستقصاء من الناحية المبدانية.

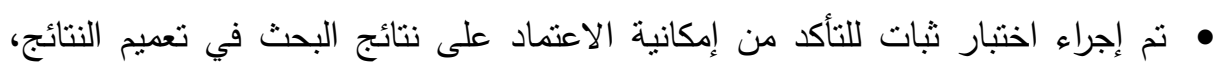

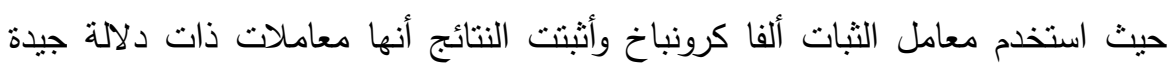
لتحقيق أهداف البحث، ويمكن الاعتماد عليها في تعميم النتائج على مجتمع الدراسة.

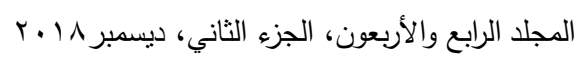


الخطوة الثالثة: استيفاء بيانات قوائم الاستقصاء واعدادها للتحليل الإحصائسم: قام الباحثون في هذه المرحلة باستيفاء بيانات قوائم الاستقصاء من مفردات البحث بعد أن تم إعدادها في لإنياء

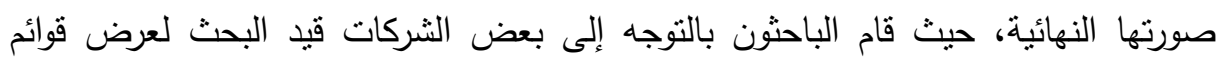
الاستقصاء على بعض العاملين عن طريق المقابلات الثخصية التى أجروها معهم. هذا وقد تم مراجعة قوائم الاستقصاء بعد أن تمت الإجابة عليها، ثم قام الباحتون بإدخال

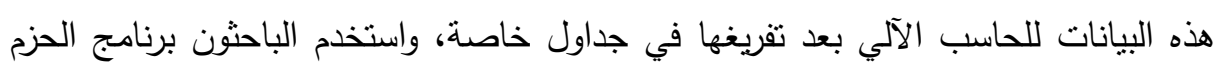
الإحصائية (SPS v25) في إجراء التحليل الإحصائي لبيانات الدراسة الميدانية.

\section{أساليهب التطليل الإحسائيه}

إعتمد الباحثون على الأساليب التالية:

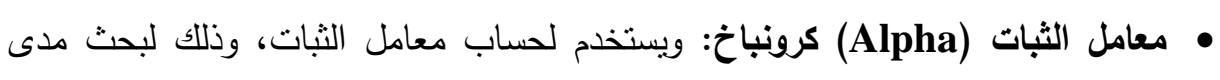
إمكانية الإعتماد على نتائج الدراسة الميدانية في تعميم النتائج.

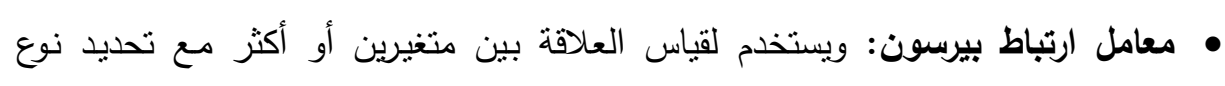
العلاقة وقوتها.

• أسلوب الانحدار البسيط: ويستخدم لحساب معاملات الانحدار للمتغير المستقل على

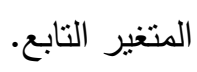

\section{مبوض الهAهA}

الحدود الزمنية: تتمنل الحدود الزمنية للاراسة في الفترة من أول يناير عام ^ ا ـ ب الي يوليو

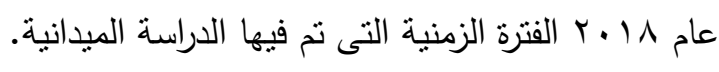
الحدود المكانية: كما تتمثل الحدود المكانية للبحث في الثركة القابضة لمياه الثرب

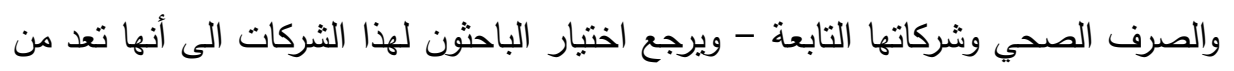
أهم الثركات العاملة في القطاع التتموي في مصر من حيث توافر الإمكانات والكوادر الفنية

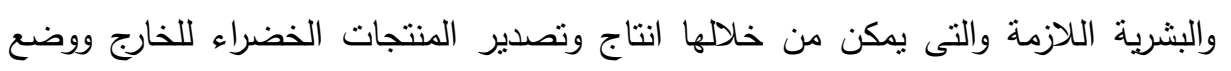


نموذج يحتذى به في كافة الثركات الأخرى في مصر وكذللك للصلة الوثيقة التي تربط

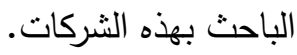

الحدود البشرية: وقد شملت الدراسة الحدود البشرية العاملين بالثركة القابضة لمياه الثرب والصرف الصحي وشركاتها التابعة، وقد تم اختبار الفئات الثناثة (مديرون- أخصائيون وفنيون - مشرفون على الإنتاج وملاحظون)، حيث أن لديهم القدرة على فهم وتحليل محاور الدراسة المختلفة.

الحدود العلمية: اقتصرت الدراسة على دراسة أثز تنبي إنتاج الغاز الحيوي من حمأة الصرف الصحي بأبعادها الخمسة على التتمية المستدامة بأبعاده الثلاثة المذكورة، بالتطبيق إنتاج على الثركة القابضة لمياه الثرب والصرف الصحي وشركاتها التابعة.

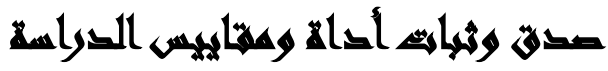

قام الباحثون بإجراء اختبارات الصدق والثبات لقائمة الاستقصاء بغرض بحث مدى

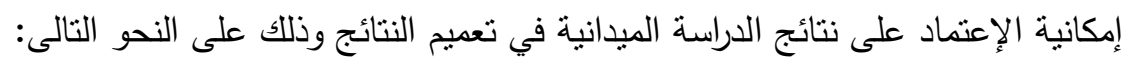
نم إجراء اختبار الثبات (Alpha) لمحتويات قائمة الاستقصاء، للتأكد من إمكانية

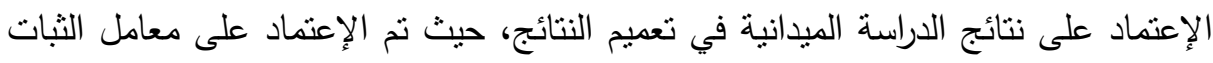

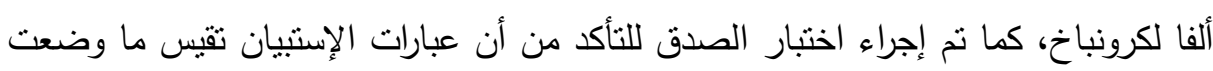

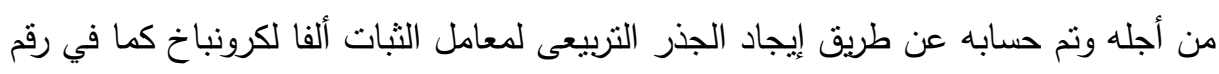

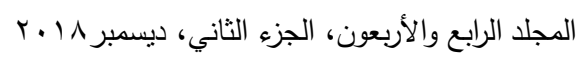


جدول رقم(ץ): معاملى الثبات لألفا كرونباخ والصدق الذاتى لاستمارة الاستقصاء

\begin{tabular}{|c|c|c|c|c|}
\hline معامل الصدق & $\begin{array}{c}\text { معامل } \\
\text { (Alpha) } \\
\text { (Alpa) }\end{array}$ & 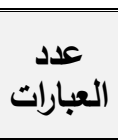 & البيـان & المحاور \\
\hline$\cdot, 9 \cdot 9$ & $\cdot, \wedge T \wedge$ & $r \leq$ & إنتاج الغاز الحيوي من حماة & الأول \\
\hline$\cdot, 919$ & $\cdot, \wedge \leq \varepsilon$ & $\mathrm{V}$ & السياسة البيائية & 1 \\
\hline$\cdot, \wedge 7 \wedge$ & $\cdot, \mathrm{VOT}$ & 0 & التخطبط & T \\
\hline$\cdot, 9 \leqslant \leqslant$ & $\cdot$, A9Y & 7 & السياسة الاقتصادية & $\mu$ \\
\hline •, АтT & $\cdot, \mathrm{V} \leqslant 0$ & $\mu$ & الآليات الإدارية & $\varepsilon$ \\
\hline$\cdot, 9 \xi$ & $\cdot, \wedge \wedge \xi$ & $\mu$ & المراجعة الإدارية والبيئية & 0 \\
\hline$\cdot, 9 \vee \Gamma$ & $\cdot, 9 \leqslant V$ & TO & التتمية المستخامة & 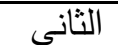 \\
\hline$\cdot, 940$ & $\cdot$, AVO & $\Lambda$ & البعد البيائي & $T$ \\
\hline$\cdot, 941$ & $\cdot$, ATV & 1. & البعد الاقتصادي والتقني & $r$ \\
\hline$\cdot, 9 Y Y$ & $\cdot, 101$ & $\mathrm{~V}$ & البعد الاجتماعى & $\mu$ \\
\hline
\end{tabular}

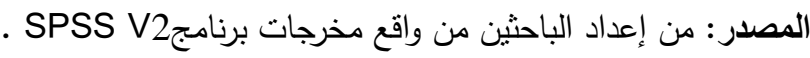

وباستعراض الجدول رقم (2) يتضح أن قيم معامل الثبات مقبولة لجميع المحاور ، حيث ليث تضمنت استمارة الاستقصاء محورين رئيسيين وكل محور يتكونا من مجموعة من الأبعاد تأخذ

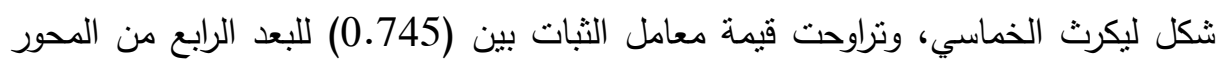
الأول " الآليات الإدارية "و (0.947) للمحور الثاني " التتمية المستدامة "'".

وباستعراض جدول رقم (2) تراوحت قيمة معامل الصدق بين (0.863) للبعد الرابع من الإن الإدان

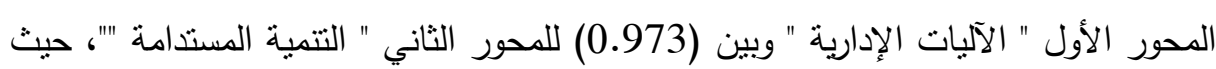
أن قيمة معامل الصدق الذاتي هي الجذر التربيعي لقيم معامل الثبات.

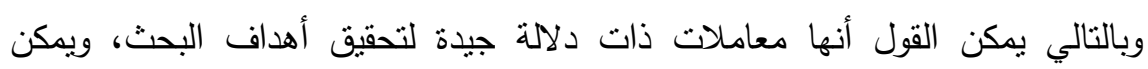

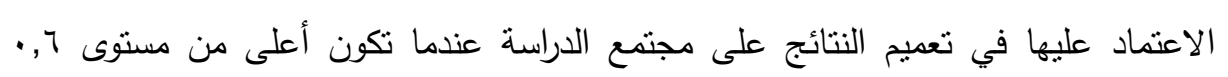

.(Riege, 2003) 


\section{نئائج الصواسما}

اختبار فروض الاراسة: لاختبار فروض الدراسة تم اختبار وجود علاقة ارتباط معنوية بين

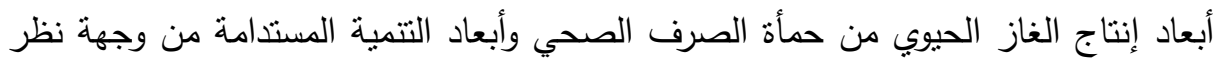

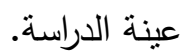
قام الباحثون باستخدام معامل ارتباط بيرسون لتحديد نوع وقوة العلاقة بين أبعاد إنتاج

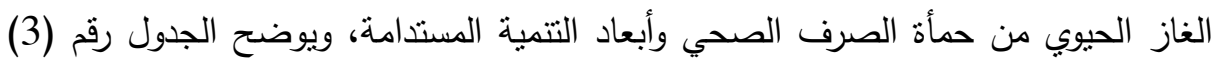
النتائج الخاصة بنلك العلاقة: جدول رقم(ץ): معاملات إرتباط بيرسون بين أبعاد إنتاج الغاز الحيوي من حمأة الصرف

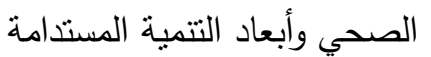

\begin{tabular}{|c|c|c|c|}
\hline البعد الاجتماعى & البعد الاقتصادي والتقتى & البعد البيأي & \\
\hline *ฯฯร. & **VYर. & "**qrV. & السباسة البيئية \\
\hline *yor. & *ятr. & **97Y. & التخطيط \\
\hline *ฯマV・. & $* * \vee \vee$ V & **quร. & السياسة الاقتصصادية \\
\hline *ףrו. & *ๆミ). & **ar।. & آلآليات الإدارية \\
\hline *09T. & *ฯฯV. & $* * q \curlyvee \wedge$. & المراجعة الإدارية والبيئية \\
\hline
\end{tabular}

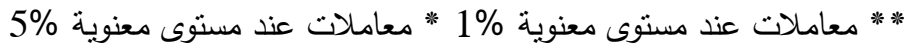

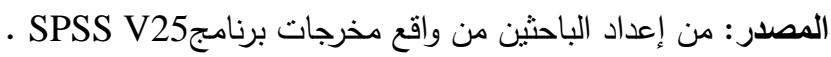
يتضح من الجدول رقم (3) وجود إرتباط طردى قوى بين (التخطيط) كأحد أبعاد إنتاج

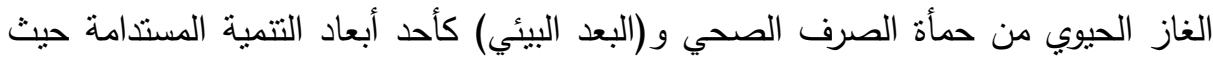
بلغت قيمة معامل الإرتباط (0.962) ومعنوى عند مستوى معنوية 1\%، وتوجد علأ علاقة طرديه قوية بين (السياسة البيئية) كأحد أبعاد إنتاج الغاز الحيوي من حمأة الصرف الصنئ الصحي و (البعد

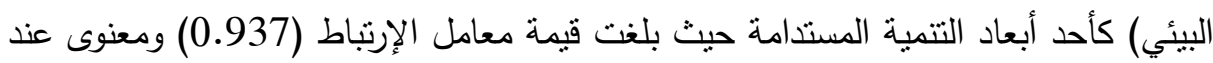
مستوى معنوية 1\%، ويتضح من الجدول وجود علاقة طردية قوية بين (المراجعة الإدارية والبيئية) كأحد أبعاد إنتاج الغاز الحيوي من حمأة الصرف الصحي و (البعد البيئي) كأحد أبعاد

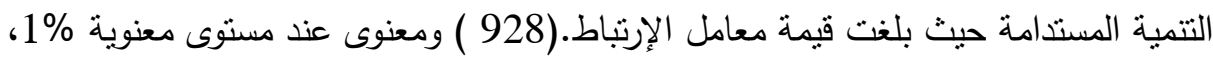

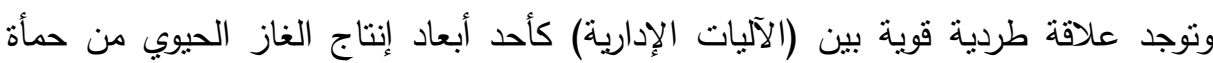

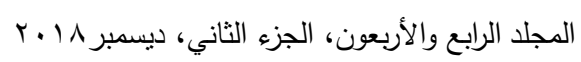


الصرف الصحي و(البعد البيئي) كأحد أبعاد التتمية المستدامة حيث بلغت قيمة معامل الإرتباط (0.921) ومعنوى عند مستوى معنوية 1\%، وكانت أقل قيمة لمعامل الارتباط بين

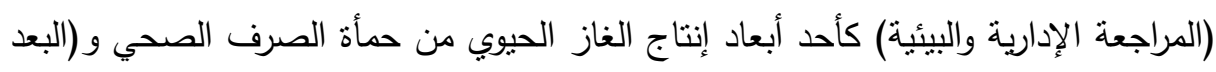

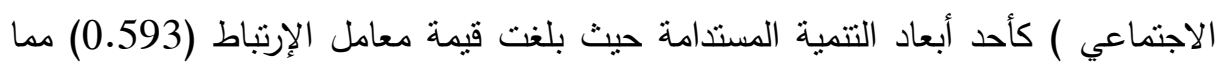
يدل على وجود علاقة طردية متوسطة بين المتغيرين ومعنوية عند مستوى معنوية 5\%.

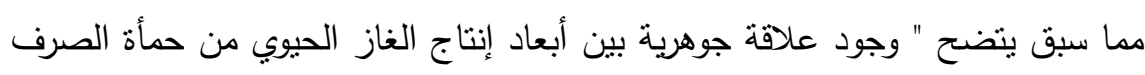

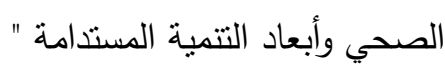
اختبار الفرض الرئيسي الأول: والذي ينص على أنه: " لا يوجد تأثثراً ذات دلالة إحصائية للسياسة البيئية كأحد أبعاد إنتاج الغاز الحيوي من حمأة الصرف الصدي الصحي على أبعاد التتمية

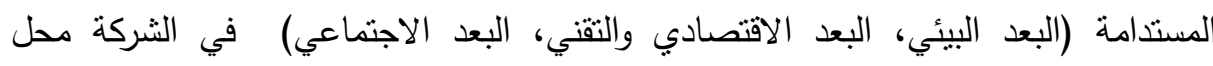
الدراسة."

لاختبار هذا الفرض نم استخدام الإنحدار البسيط يعرض جدول رقم (4) تقديرات نماذج الإنحدار البسيط لإنحدار المتغيرات التابعة (متوسط آراء العينة حول أبعاد التتمية المستخامة) على السياسة البيئية. جدول رقم( ) : ثقديرات نماذج الانحدار البسيط للسياسة البيئية

\begin{tabular}{|c|c|c|c|c|c|c|}
\hline \multicolumn{4}{|c|}{ التقديرات } & \multirow{2}{*}{$\begin{array}{c}\mathbf{F} \\
\text { (sig.) }\end{array}$} & \multirow{2}{*}{ 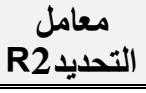 } & \multirow{2}{*}{ المتغيرات التابعة } \\
\hline Sig. & $\mathbf{t}$ & $\beta$ & & & & \\
\hline$\cdot, \ldots$ & $1, \leqslant 0 V$ & $\cdot .094$ & الثابت & \multirow{2}{*}{ VY,Tos } & \multirow[b]{2}{*}{$\cdot, \wedge \wedge}$. & \multirow[b]{2}{*}{ البعد البيئي } \\
\hline$\cdot, \cdots$ & $1,0.7$ & $\cdot, \wedge \wedge \wedge$ & البياسية & & & \\
\hline$\cdot, \cdots$ & $1,11 \varepsilon$ & $\cdot, 997$ & الثابت & \multirow{2}{*}{$\begin{array}{l}\mid r, r \cdot 1 \\
\cdot, \cdot r\end{array}$} & \multirow[b]{2}{*}{$\cdot, V \leq 0$} & \multirow{2}{*}{ الاقتصادي } \\
\hline$\cdot, \cdots$ & rוז,r & $\cdot, \vee \vee \backslash$ & البياسية & & & \\
\hline$\cdot, \cdots$ & 1,911 & 1,71 & الثابت & \multirow{2}{*}{$\begin{array}{l}\nearrow, \vee \backslash 7 \\
\cdot, \cdots\end{array}$} & \multirow[b]{2}{*}{$\cdot, \wedge 19$} & \multirow{2}{*}{ الاجتماعي البعد } \\
\hline$\cdot, \cdots$ & $r, 091$ & $\cdot, 0 \wedge \varepsilon$ & البياسية & & & \\
\hline
\end{tabular}

المصدر: من إعداد الباحثين من واقع مخرجات برنامجSPSS V25 
يتضح من الجدول رقم (4) معنوية نموذج إنحدار البعد البيئي على السياسة البيئية من

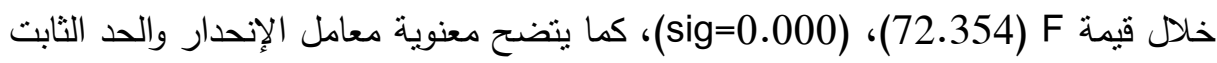
عند مستوى معنوية 5\%. وبلغت قيمة معامل التحديد (0.880) مما يدل على أن المتغير المستقل (السياسة البيئية) يفسر \% 88.0 من التغيرات التى تحدث في المتغير التابع (متوسط آراء العينة حول البعد البيئي).

معنوية نموذج إنحدار البعد الاقتصادي والتقني على السياسة البيئية من خلال قيمة

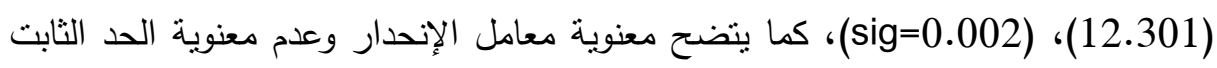

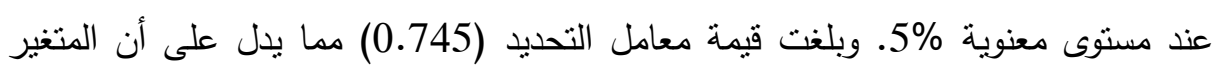
المسنقل (السياسة البيئية) يفسر \% 74.45 من التغيرات التى تحدث في المتغير التابع (البعد الاقتصادي والثقني).

F معنية نموذج إنحدار البعد الاجتماعي على السياسة البيئية من خلال قيمة

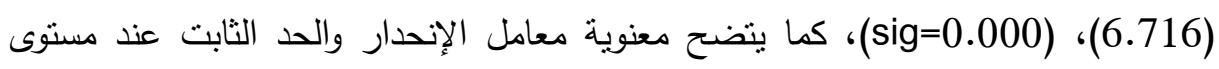
معنوية 5\%، 10\%. وبلغت قيمة معامل التحديد (0.819) مما يدل على أن المتغير المستقل (السياسة البيئية) يفسر 81.9\% من التغيرات التى تحدث في المتغير التابع (البعد

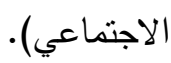
يتضح من الجدول رقم (4) ان أثنارة معاملات الإنحدار موجبة مما بدل على وجود

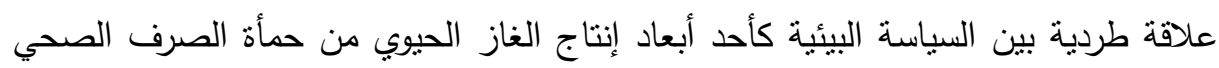

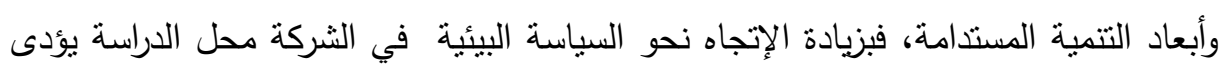
ذلك إلى زيادة التتمية المستدامة لدي العاملين.

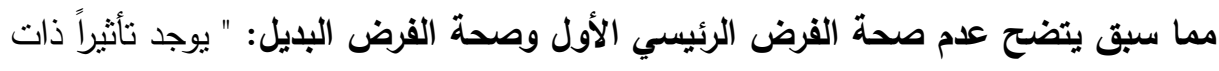

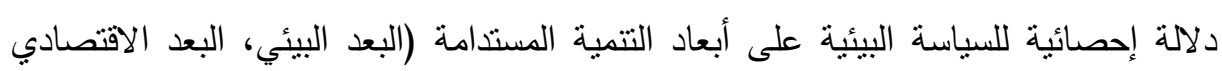

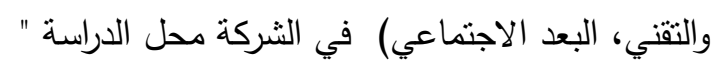


اختبار الفرض الرئيسي الثانى: " لا يوجد تأثثراً ذات دلالة إحصائية للتخطيط كأحد أبعاد إنتاج الغاز الحيوي من حمأة الصرف الصحي على أبعاد التتمية المستدامة (البعد البيئي،

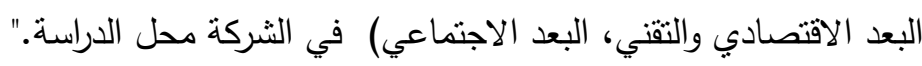

لاختبار هذا الفرض نم استخدام الإنحدار البسيط يعرض جدول رقم (5) تقديرات نماذج الته

الإنحدار البسيط لإنحدار المتغيرات التابعة (متوسط آراء العينة حول أبعاد التتمية المستدامة)

على التخطيط كأحد أبعاد إنتاج الغاز الحيوي من حمأة الصرف الصحي. جدول رقم(ه): ثقديرات نماذج الإنحدار البسيط للنخطيط منطيط

\begin{tabular}{|c|c|c|c|c|c|c|}
\hline \multicolumn{4}{|c|}{ التقديرات } & \multirow{2}{*}{$\begin{array}{c}\mathbf{F} \\
\text { (sig.) }\end{array}$} & \multirow{2}{*}{$\begin{array}{c}\text { التحديد } \\
\text { R2 } \\
\end{array}$} & \multirow[b]{2}{*}{ المتغيرات التابعة } \\
\hline Sig. & $\mathbf{t}$ & $\beta$ & & & & \\
\hline$\cdot, \ldots$ & $r, \cdot T_{1}$ & $\cdot, 9 \cdot V$ & الثنابت & \multirow{2}{*}{$\begin{array}{c}|r T, r V| \\
.\end{array}$} & \multirow{2}{*}{$\cdot, 9 Y 0$} & \multirow{2}{*}{ البعد البيئي } \\
\hline$\cdot, \ldots$ & $11,1 \cdot V$ & $1, r \leqslant 9$ & التخطبط & & & \\
\hline,$\ldots$ & ., & $\cdot, 1 \wedge r$ & الثابت & \multirow{2}{*}{$\begin{array}{l}V, A Y \leq \\
\cdot, \cdot 19\end{array}$} & \multirow{2}{*}{$\cdot, \vee 00$} & \multirow{2}{*}{ البعد الالقتصنادي } \\
\hline$\cdot, \ldots$ & $r, \vee 9 V$ & $\cdot, 971$ & التخطيط & & & \\
\hline$\cdot, \ldots$ &., $0 \mathrm{~V}$ & $\cdot, 7 \wedge 0$ & الثابت & $v, r q 1$ & \multirow{2}{*}{$\cdot, 110$} & \multirow{2}{*}{ البعد الاجتماعي } \\
\hline$\cdot, \ldots$ & $r, v \backslash q$ & $\cdot, \wedge Y \varepsilon$ & التخطبط & $\cdot, \cdot Y Y$ & & \\
\hline
\end{tabular}

المصدر: من إعداد الباحثين من واقع مخرجات برنامج.SPSS V25

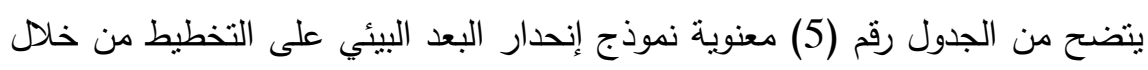

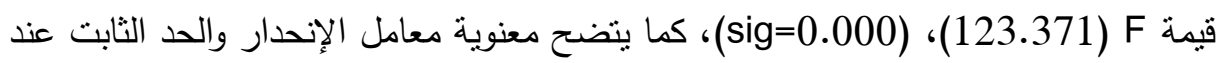
مستوى معنوية 5\%. وبلغت قيمة معامل التحديد (0.925) مما يدل على أن المتغير المستقل (التخطيط كأحد أبعاد إنتاج الغاز الحيوي من حمأة الصرف الصحي) يفسر التغيرات التى تحدث في المتغير التابع (متوسط آراء العينة حول البعد البيئي).

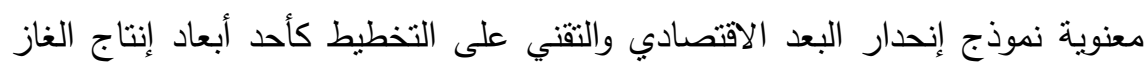

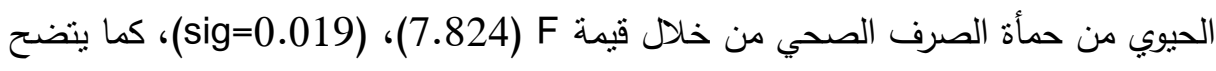

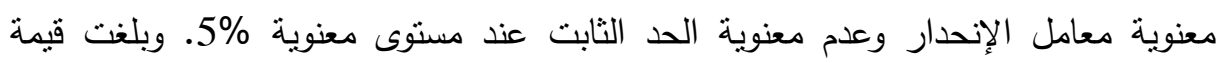
معامل التحديد (0.755) مما بدل على أن المتغير المستقل (التخطيط كأحد أبعاد إنتاج الغاز

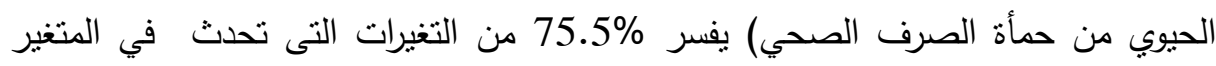
التابع (متوسط آراء العينة حول البعد الاقتصادي والتقني). 
معنوية نموذج انحدار البعد الاجتماعي على التخطبط كأحد أبعاد إنتاج الغاز الحيوي

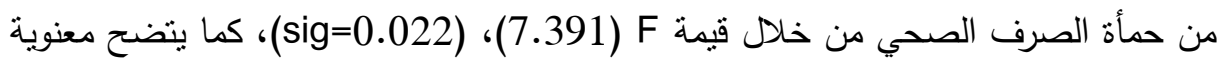
معامل الإنحدار وعدم معنوية الحد الثابت عند مستوى معنوية 5\%، وبلغت قيمة معامل التحديد (0.815) مما يدل على أن المتغير المسنقل (التخطيط كأحد أبعاد إنتاج الغاز الحيوي

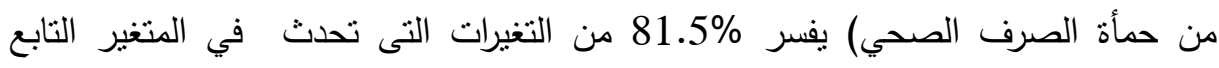
(متوسط آراء العينة حول البعد الاجتماعي).

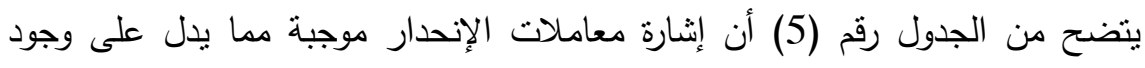
علاقة طردية بين التخطيط كأحد أبعاد إنتاج الغاز الحيوي من حمأة الصرف الصدامي الصحي وبين

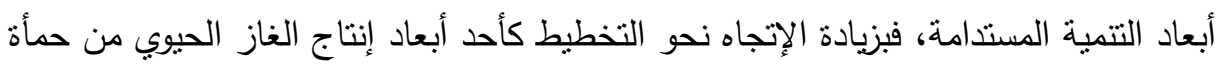
الصرف الصحي في الثركة محل الدراسة يؤدى ذلك الى زيادة التتمية المستدامة.

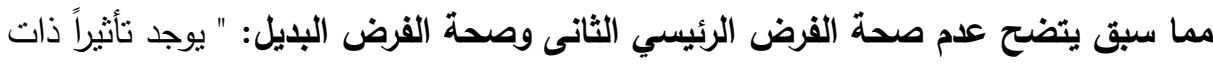

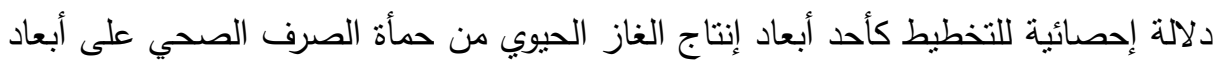
التتمية المستدامة (البعد البيئي، البعد الاقتصادي والتقني، البعد الاجنماعي) في الثركة محل الدراسة." الفرض الرئيسي الثالث: لا يوجد ثأثثراً ذات دلالة إحصائية للسياسة الاقتصادية كأحد أبعاد إنتاج الغاز الحيوي من حمأة الصرف الصحي على أبعاد التتمية المستدامة (البعد البيئي،

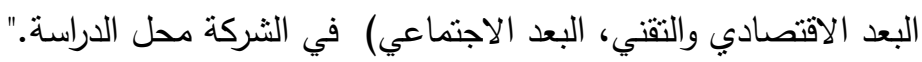

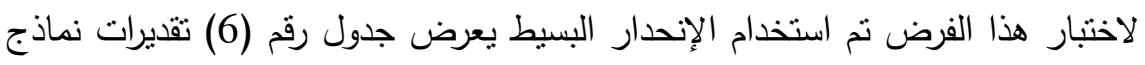
الإنحدار البسيط لإنحدار المتغيرات التابعة (متوسط آراء العينة حول أبعاد التتمية المستدامة) على السياسة الاقتصادية كأحد أبعاد إنتاج الغاز الحيوي من حمأة الصرف الصنئ الصدي. 
نامز سامي وآخرون

جدول رقم(7): تقديرات نماذج الإنحدار البسيط للسياسة الاقتصادية

\begin{tabular}{|c|c|c|c|c|c|c|}
\hline \multicolumn{4}{|c|}{ التقديرات } & \multirow{2}{*}{$\begin{array}{c}\mathbf{F} \\
\text { (sig.) }\end{array}$} & \multirow{2}{*}{ 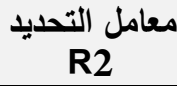 } & \multirow{2}{*}{ المتغيرات } \\
\hline Sig. & $t$ & $\beta$ & & & & \\
\hline., 007 & $\cdot, 7,9$ & T & الثابت & \multirow[b]{2}{*}{$\begin{array}{c}71, Y Y T \\
.\end{array}$} & \multirow[b]{2}{*}{$\cdot, A V Y$} & \multirow[b]{2}{*}{ البعد البيئي } \\
\hline • & $\Lambda, Y^{\prime}$ & $1, .97$ & الاقتصنادية & & & \\
\hline., $90 \mathrm{~V}$ &., .00 &., .01 & الثابت & \multirow[b]{2}{*}{$\begin{array}{l}17,7 \cdot r \\
\cdot, \cdots r\end{array}$} & \multirow[b]{2}{*}{$\cdot, \vee \wedge \wedge$} & \multirow{2}{*}{ الاقتصادي } \\
\hline$\cdot, \cdots r$ & $r, \wedge \wedge)$ & $1, \cdot 17$ & الاقتصنادية & & & \\
\hline$\cdot, \sum Y$ & $\cdot, \wedge \leqslant Y$ & $\cdot, 9,1$ & الثابت & \multirow{2}{*}{$\begin{array}{l}\lambda, 109 \\
\therefore, .1 V\end{array}$} & \multirow[b]{2}{*}{$\cdot, 919$} & \multirow{2}{*}{ الاجنماعي } \\
\hline$\cdot, \cdot \mid \mathrm{V}$ & $r, \wedge 07$ & -, V70 & الاقتصبادية & & & \\
\hline
\end{tabular}

المصدر: من إعداد الباحثين من واقع مخرجات برنامج SPSS V25

يتضح من الجدول رقم (6) معنوية نموذج إنحدار البعد البيئي على السياسة الاقتصادية

من خلال قيمة F Fig=0.000)، (68.226)، كما يتضح معنوية معامل الإنحدار وعدم معنوية الحد الثابت عند مستوى معنوية 5\%. وبلغت قيمة معامل التحديد (0.872) مما يدل على أن المتغير المستقل (السياسة الاقتصادية كأحد أبعاد إنتاج الغاز الحيوي من مدأة الصرف الصحي) يفسر 87.2\% من التغيرات التى تحدث في المتغير التابع (متوسط آراء

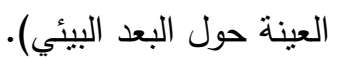

معنوية نموذج إنحدار البعد الاقتصادي والثقني على السياسة الاقتصادية كأحد أبعاد

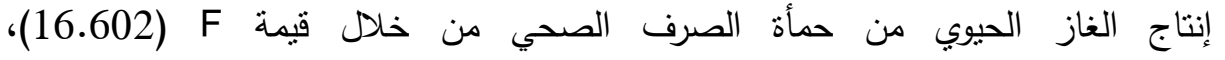
،(sig=0.003)

كما يتضح معنوية معامل الانحدار وعدم معنوية الحد الثابت عند مستوى معنوية 5\%. وبلغت قيمة معامل التحديد (0.788) مما يدل على أن المتغير المستقل (السياسة الاقتصادية

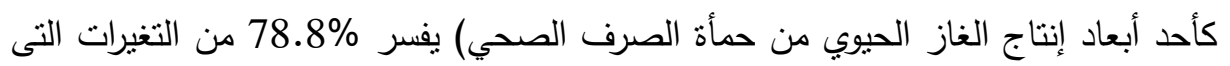
تحدث في المتغير التابع (متوسط آراء العينة حول البعد الاقتصادي والتقني). معنوية نموذج انحدار البعد الاجتماعي على السياسة الاقتصادية كأحد أبعاد إنتاج الغاز لعانه

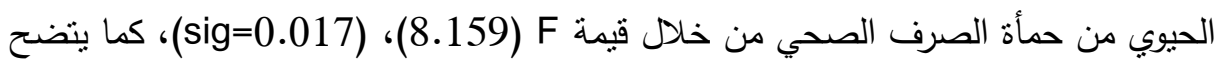

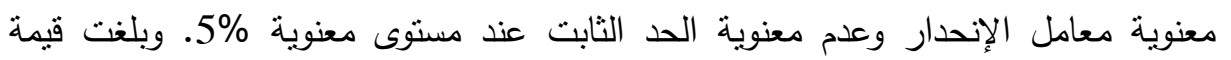


معامل التحديد (0.919) مما يدل على أن المتغير المستقل (السياسة الاقتصادية كأحد أبعاد

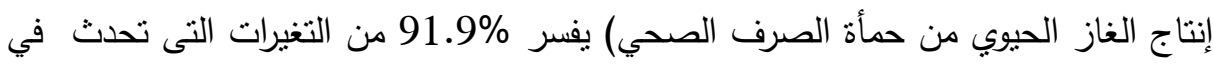

$$
\text { المتغير التابع (متوسط آراء العينة حول البعد الاجتماعي). }
$$

كما يتضح من الجدول رقم (6) أن إثشارة معاملات الإنحدار موجبة مما يدل على وجود علاقة الئد طردية بين السياسة الاقتصادية كأحد أبعاد إنتاج الغاز الحيوي من حمأة الصرف الصحي وبين أبعاد الصاد الصاديا

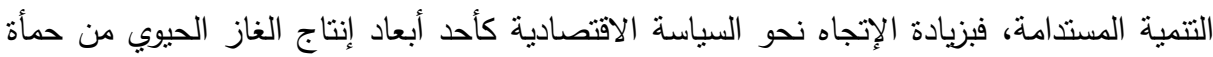
الصرف الصحي في الثركة محل الدراسة يؤدى ذلك إلى زيادة التنمية المستدامة. مما سبق يتضح عدم صحة الفرض الرئيسي الثالث من الفرض الرابع وصحة الثرادئ الفرض

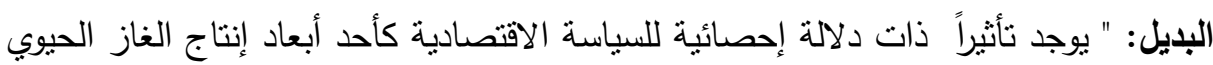

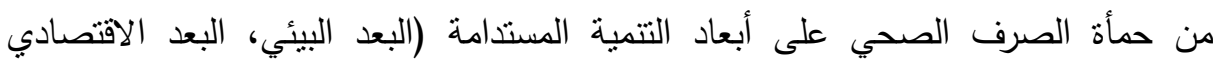
والتقني، البعد الاجتماعي) في الثركة محل الدراسة." الفرض الرئيسي الرابع:" لا يوجد تأثيراً ذات دلالمة إحصائية للآلّات الإدارية كأحد أبعاد إنتاج

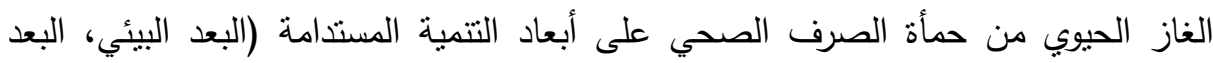
الاقتصادي والثقني، البعد الاجتماعي) في الثركة محل الدراسة." لاختبار هذا الفرض تم استخدام الإنحدار البسيط، ويعرض جدول رقم (7) تقديرات نماذج الإنحدار البسيط لإنحدار المتغيرات التابعة (متوسط آراء العينة حول أبعاد التتمية المستدامة) على الآليات الإدارية. جدول رقم(V): نقديرات نماذج الإنحدار البسيط للآليات الإدارية

\begin{tabular}{|c|c|c|c|c|c|c|}
\hline \multicolumn{4}{|c|}{ التقديرات } & \multirow{2}{*}{$\begin{array}{c}\mathbf{F} \\
\text { (sig.) }\end{array}$} & \multirow{2}{*}{$\begin{array}{c}\text { معامل التحديد } 2 \\
\text { R2 }\end{array}$} & \multirow{2}{*}{ المتغيرات التابعة } \\
\hline Sig. & $\mathbf{t}$ & $\beta$ & & & & \\
\hline$\cdot, \ldots$ & $r \wedge, \Sigma \Gamma$ & $0, \leqslant 0 \leqslant$ & الثابت & \multirow{2}{*}{$\begin{array}{l}07,17 \\
., \ldots\end{array}$} & \multirow{2}{*}{$\cdot, \wedge \leq 9$} & \multirow{2}{*}{ البعد البيئي } \\
\hline$\cdot, \ldots$ & $\vee, \leq q \leq$ & $\cdot, 091$ & الآليات الإدارية & & & \\
\hline$\cdot, \ldots$ & $14, .19$ & $0, \cdot 17$ & الثابت & \multirow{2}{*}{$\begin{array}{l}7,971 \\
\cdot, .90\end{array}$} & \multirow{2}{*}{$\cdot, V Y T$} & \multirow{2}{*}{ البعد الاقتصادي } \\
\hline$\cdot, \cdot$. 0 & r,Trᄉ & $\cdot, \leqslant 70$ & الآليات الإدارية & & & \\
\hline$\cdot, \cdots$ & $M, \mid T \leq$ & $\varepsilon, \wedge \wedge \wedge$ & الثابت & \multirow{2}{*}{$\begin{array}{l}7, T \cdot r \\
\cdot, \cdot r \Lambda\end{array}$} & \multirow[b]{2}{*}{$\cdot, \wedge \leq r$} & \multirow[b]{2}{*}{ البعد الاجتماعي } \\
\hline$\cdot, \cdot r \wedge$ & $r, 079$ & $\cdot, \Gamma 9 \wedge$ & الآليات الإدارية & & & \\
\hline
\end{tabular}

المصدر : من إعداد الباحثين من واقع مخرجات برنامجSPS V25.

$$
\text { المجلد الرابع والأربعون، الجزء الثاني، ديسمبر \1 ـ r }
$$


يتضح من الجدول رقم (7) معنوية نموذج إنحدار البعد البيئي على الآليات الإدارية من

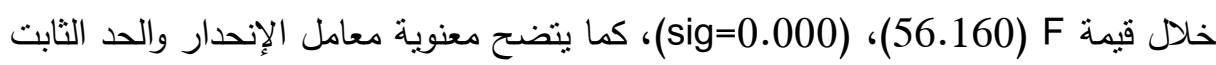
عند مستوى معنوية 5\%. وبلغت قيمة معامل التحديد (0.849) مما يدل على أن المتغير المستقل (الآليات الإدارية) يفسر (متوسط آراء العينة حول البعد البيئي).

معنوية نموذج إنحدار البعد الاقتصادي والتقني على الآليات الإدارية من خلال قيمة

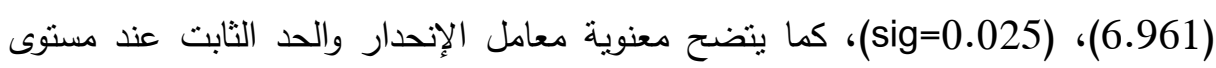
معنوية 5\%. وبلغت قيمة معامل التحديد (0.723) مما يدل على أن المتغير المستقل (الآليات الإدارية) يفسر 72.3\% من التغيرات التى تحدث في المتغير التابع (متوسط آراء العينة حول البعد الاقتصادي والتقني). معنوية نموذج إنحدار البعد الاجتماعي على الآليات الإدارية من خلافل قيمة

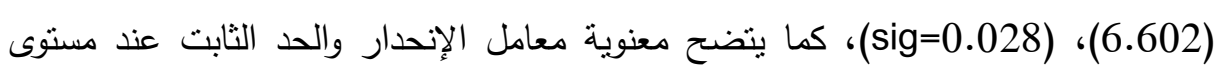
معنوية 5\%، وبلغت قيمة معامل التحديد (0.842) مما بدل على أن المتغير المستقل (الآليات الإدارية) يفسر 84.2\% من التغيرات التى تحدث في المتغير التابع (متوسط آراء العينة حول البعد الاجتماعي).

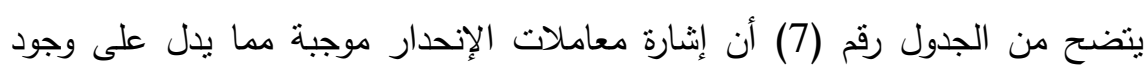

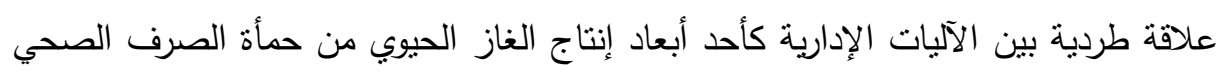

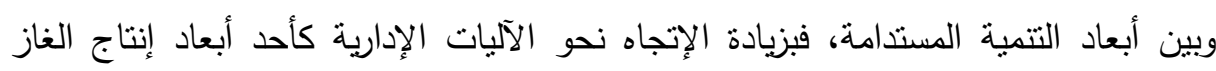

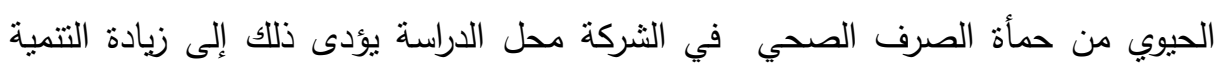
المستدامة.

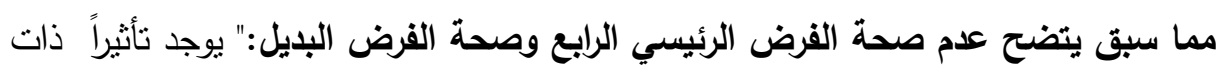

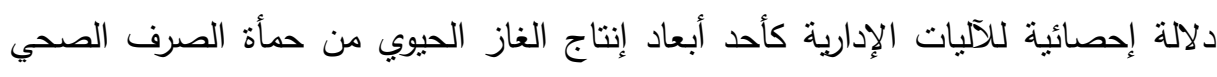

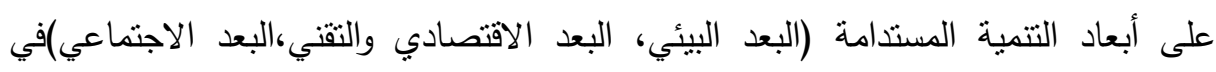

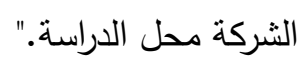


الفرض الرئيسي الخامس: " لا يوجد تأثيراً ذات دلالة إحصائية للمراجعة الإدارية والبيئية

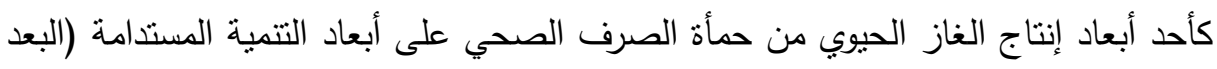

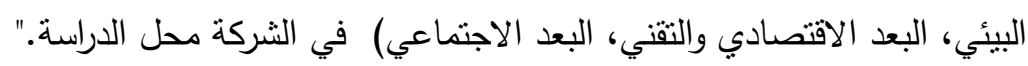

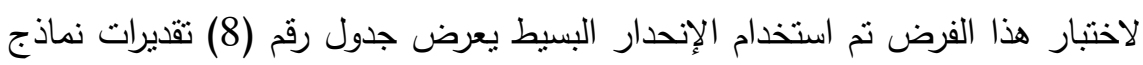
الإنحدار البسيط لإنحدار المتغيرات التابعة (متوسط آراء العينة حول أبعاد التتمية المستدامة) على المراجعة الإدارية والبيئية. جدول رقم(^): تقديرات نماذج الانحدار البسيط للمراجعة الإدارية والبيئية

\begin{tabular}{|c|c|c|c|c|c|c|}
\hline \multicolumn{4}{|c|}{ التقديرات } & \multirow{2}{*}{$\begin{array}{c}\mathbf{F} \\
\text { (sig.) }\end{array}$} & \multirow{2}{*}{$\begin{array}{c}\text { التحديدم2 R2 } \\
\text { R2 }\end{array}$} & \multirow{2}{*}{ التابعة } \\
\hline Sig. & $t$ & $\beta$ & & & & \\
\hline$\cdot, \ldots$ & TV,OTH & $0, \pi T$ & الثنابت & \multirow[b]{2}{*}{$\begin{array}{l}r, 1, \ldots 4 \\
., \ldots\end{array}$} & \multirow[b]{2}{*}{ • } & \multirow[b]{2}{*}{ البعد البيئي } \\
\hline$\cdot, \cdots$ & $\checkmark, \wedge \wedge r$ & • & الإدارية والبيئية & & & \\
\hline$\cdot, \ldots$ & $11,01 Y$ & $0, Y \neg \varepsilon$ & الثابت & \multirow[b]{2}{*}{$\begin{array}{l}\vee, 99 \vee \\
\cdot, \cdot 11\end{array}$} & \multirow[b]{2}{*}{ •, $\vee 99$} & \multirow[b]{2}{*}{ البعد الالقتصنادي } \\
\hline$\cdot, \cdot 1 \wedge$ & $\uparrow, \Lambda \uparrow \wedge$ & $\cdot, 00$ & الإدارية والبيئية & & & \\
\hline$\cdot, \cdots$ & $11, \leqslant 79$ & $\varepsilon, 940$ & الثابت & \multirow{2}{*}{$\begin{array}{l}0, \varepsilon \backslash Y \\
\cdot, \cdot \leqslant Y\end{array}$} & \multirow[b]{2}{*}{ •, 9וr } & \multirow[b]{2}{*}{ البعد الاجتماعي } \\
\hline$\cdot, \cdot \leq r$ & Y,rYY & דY, & الإدارية والبيئية & & & \\
\hline
\end{tabular}

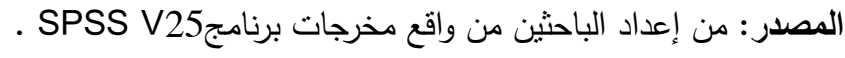
يتضح من الجدول رقم (8) معنوية نموذج إنحدار البعد البيئي على المراجعة الإدارية والبيئية من خلال قيمة Fig=0.000) (62.126)، (sig)، كما يتضح معنوية معامل الإنحدار

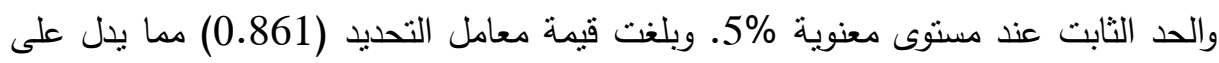
أن المتغير المستقل (المراجعة الإدارية والبيئية ) يفسر و و المتغير التابع (متوسط آراء العينة حول البعد البيئي). معنوية نموذج إنحدار البعد الاقتصادي والتقني على المراجعة الإدارية والبيئية من خلاهل

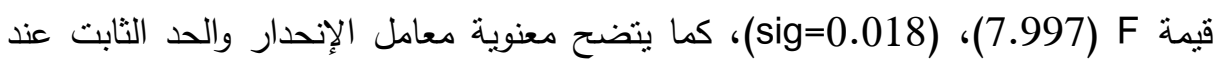

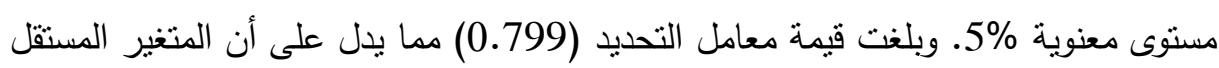


(المراجعة الإدارية والبيئية) يفسر 79.9\% من التغيرات التى تحدث في المتغير التابع (متوسط آراء العينة حول البعد الاقتصادي والتقني).

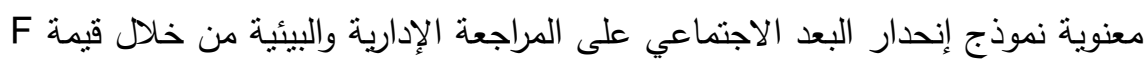

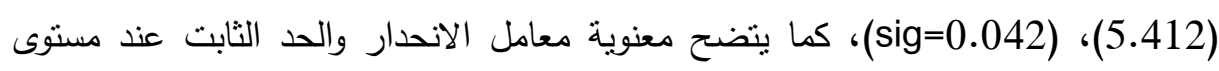

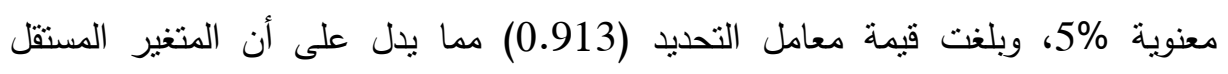

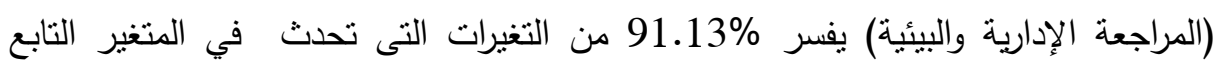
(منوسط آراء العينة حول البعد الاجنماعي).

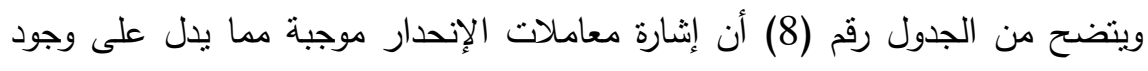

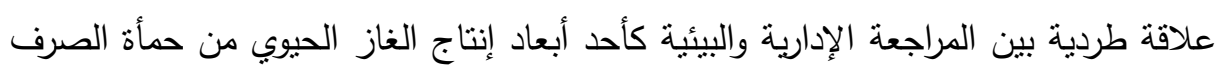

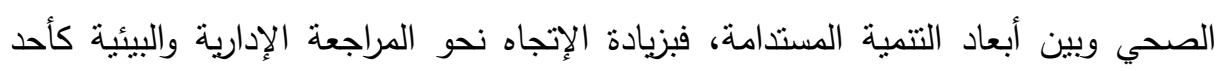

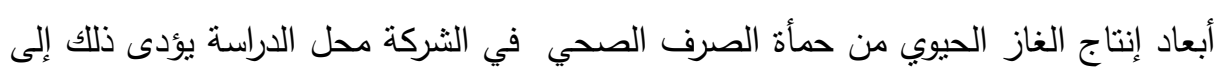
زيادة التمية المستدامة. مما سبق يتضح عدم صحة الفرض الرئيسي الخامس وصحة الفرض البديل: " يوجد تأثيراً

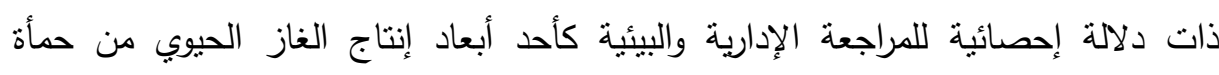

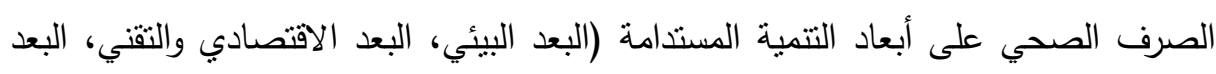

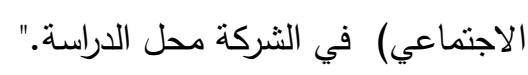

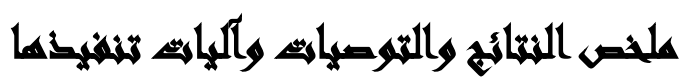

قام الباحثون بتخصيص هذا الجزء لعرض ملخص النتائج وكذلك التوصيات وآليات تنفيذها،

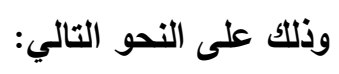
النتائحج:

ا. وجود إرتباط طردى قوى بين (التخطيط)، (السياسة البيئية)، (المراجعة الإدارية والبيئية) كأحد أبعاد إنتاج الغاز الحيوي من حمأة الصرف الصحي و (البعد البيئي) كأحد أبعاد

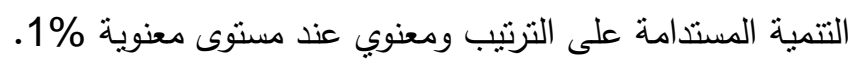




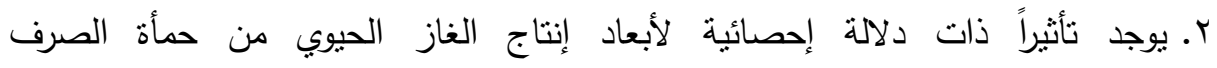

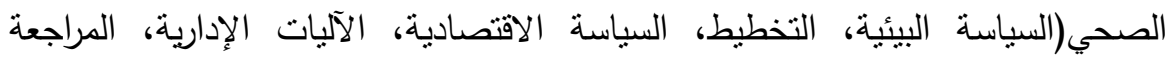

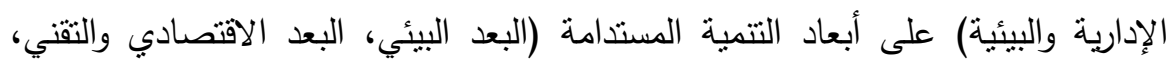
البعد الاجتماعي) في الثركة محل الدراسة.

r. تبني الثركة لإنتاج الغاز الحيوي من حمأة الصرف الصحي يرفع من التتمية المستدامة بها. ع. إنتاج الغاز الحيوي من حمأة الصرف الصحي يزيد من البعد البيئي لدي العاملين.

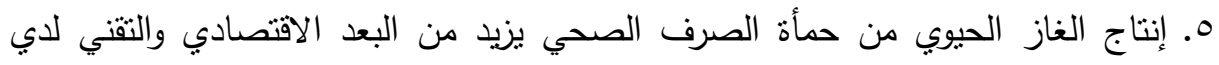
العاملين بدرجة أقل ترتيباً من أبعاد التتمية المستدامة.

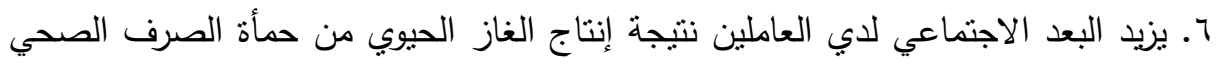
بدرجة هي الأقل ترتيباً على الإطلاق من باقي أبعاد التتمية المستدامة.

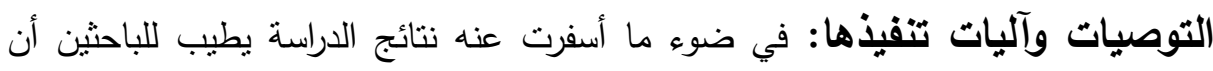
يختتموا دراستهم بتقديم مجموعة من التوصيات مع اقتراح بعض من الآليات التي يراها الباحثون ملائمة لتفعيل تللك التوصيات ووضعها موضع التتفيذ، ويمكن تلخيص هذه هنه التوصيات في البنود التالية، والجدول رقم (9) التالي يوضح توصيات الدراسة وخطوات التطبيق وجهة التنفيذ والمدى الزمني: 
جدول رقم(9): يوضح توصيات الدراسة وخطوات التطبيق وجهة التتفيذ

\begin{tabular}{|c|c|c|c|c|}
\hline الزمني & جهة التنفيذ & خطوات التطبيق & التوصية & م \\
\hline مستمرة & 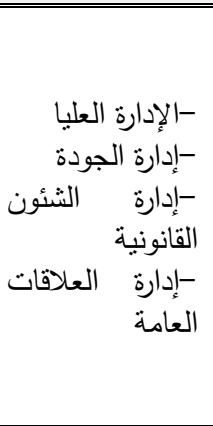 & 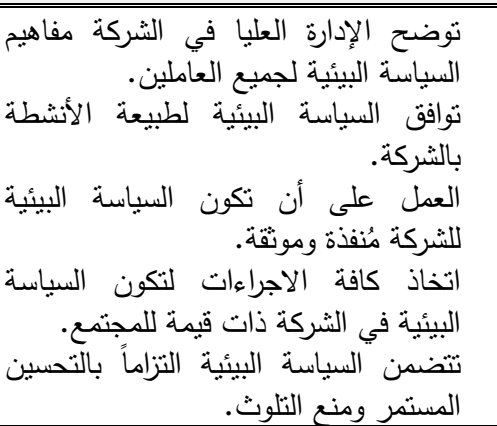 & 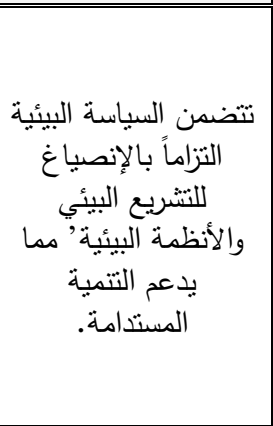 & 1 \\
\hline مستمرة & 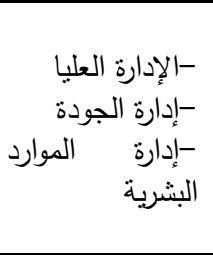 & 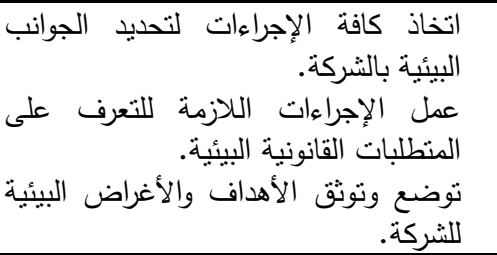 & 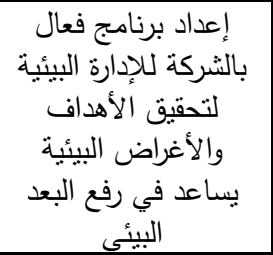 & $r$ \\
\hline مستمرة & 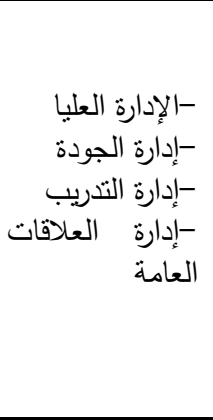 & 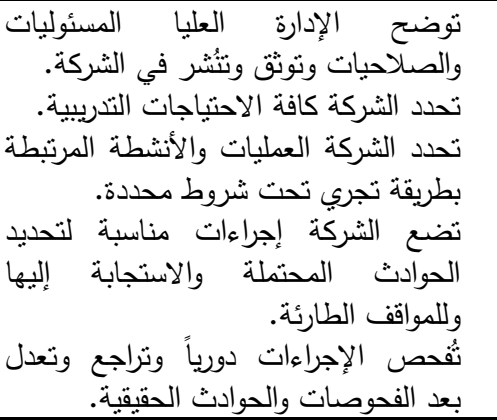 & 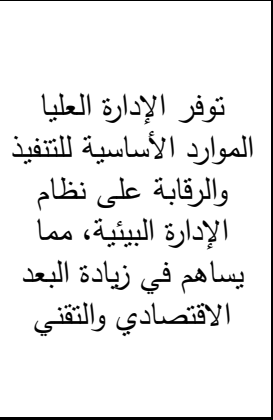 & $r$ \\
\hline مستمرة & 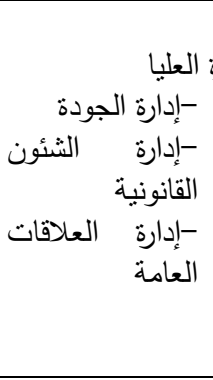 & 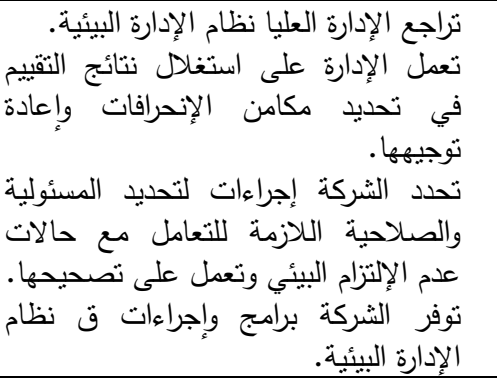 & 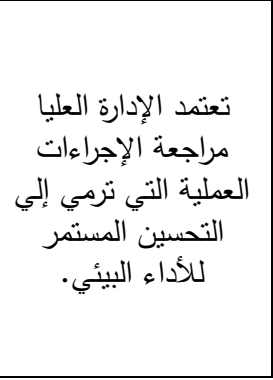 & $\varepsilon$ \\
\hline
\end{tabular}




\section{المرام}

رفعت عبد الوهاب (7 ا • ب): "الحمأة إلي طاقة "الفرص والتحديات "معرض ميونخ الدولي لمياه الثرب والصرف الصحي ميونخ، ألمانيا.

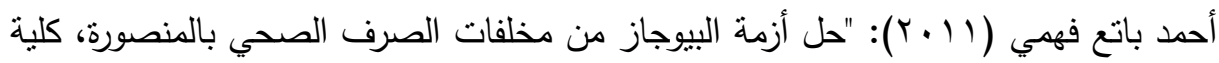

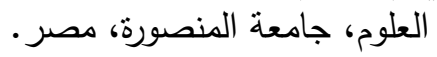

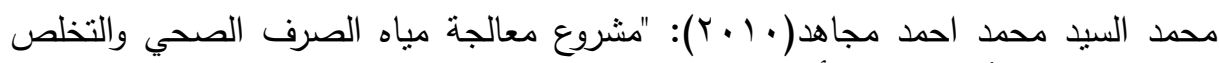

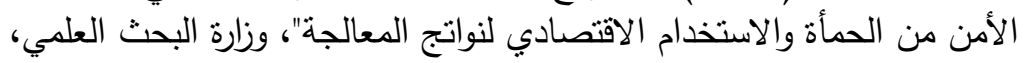

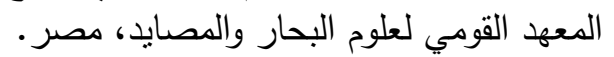

Arthurson, V. (2008): Proper Sanitization of Sewage Sludge: a Critical Issue for a Sustainable Society. Applied Environment Microbiology, 74(17), 5267-5275.

Rulkens W. (2008): Sewage sludge as a biomass resource for the production of energy: overview and assessment of the various options. Energy \& Fuels, 22, 9-15.

Smyth, B.M. and Murphy, J.D. (2011): Determining the regional potential for grass biome thane industry. Applied Energy, 88, 2037-2049.

Stone, R.J., Ekwue E.I. and Clarke, R.O. (1998): Engineering properties of sewage sludge in Trinidad. Journal of Agricultural Engineering Research, 70, 221-230.

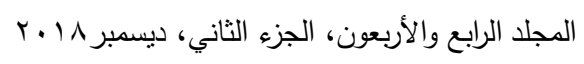


تامر سامي وآخرون

\title{
THE ECONOMIC AND ENVIRONMENTAL IMPACT OF THE PRODUCTION OF BIOGAS FROM WASTEWATER SLUDGE ON SUSTAINABLE DEVELOPMENT IN EGYPT
}

\author{
Tamer, Samey ${ }^{(1)}$; Ahmed, Mandour ${ }^{(2)}$; Hewehy M. ${ }^{(3)}$; \\ Nehal, F. Elshahat ${ }^{(4)}$ and Refat Abdel Wahaab ${ }^{(4)}$
}

1) Holding company for drinking water and sewage 2)Faculty of Commerce, Ain Shams University 3) The Institute of Environment, Ain Shams University.4) National Research Centre

\begin{abstract}
The study aimed at studying and measuring the impact of the economic and environmental of the production of biogas from sewage sludge on sustainable development in Egypt. It also aims to study the application of the Holding Company for water and wastewater and its subsidiaries in Egypt to study the production of biogas from sewage sludge, And the views of a sample of the employees of these companies, and the problem of research on the extent of the impact of the production of biogas from sewage sludge in terms of economic and environmental dimensions of sustainable development, and the researchers in this study to combine the method of extrapolation and the method of extraction The researchers used a survey list prepared for the purpose of collecting data according to the study variables, which consisted of the production of biogas from sewage sludge (independent variable) and sustainable development (a dependent variable). The researchers also used Alpha ). In addition, both simple and multiple regression analyzes were used to analyze the field study data using a sample of 376 individuals. The researchers found several results that showed a statistically significant effect between all dimensions of biogas production The researchers also highlighted the importance of adopting biogas production from sludge sludge to support the 460

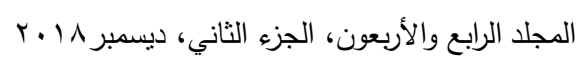




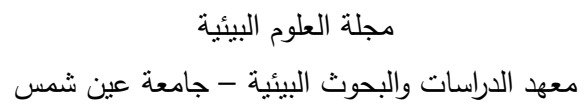

sustainable development of the Holding Company for Drinking Water and Sanitation and its subsidiaries. The researchers recommended a number of recommendations, including: Environmental policy includes a commitment to the formulation of environmental legislation and regulations, Which supports sustainable development and the development of an effective corporate environmental and economic management program for the production of biogas from sewage sludge to support sustainable development. 